\title{
1 Strontium incorporation during calcite growth: Implications \\ for chemical mapping using friction force microscopy
}

\author{
Pablo Cubillas ${ }^{1}$, Xiaoming $\mathrm{Hu}$ and Steven R. Higgins*
}

Department of Chemistry, Wright State University, 3640 Col. Glenn Hwy. 45435

Dayton, $\mathrm{OH}$. USA.

${ }^{1}$ Present address: Department of Earth Sciences, Durham University. Science Site, DH1 3LE, Durham, UK.

*Corresponding author: steven.higgins@wright.edu, 937-775-2479, fax: 937-7752717

Abstract

Sr partitioning on calcite crystals growing from $\mathrm{Ca}^{2+}-\mathrm{Sr}^{2+}-\mathrm{CO}_{3}{ }^{2-}$ solutions was studied by means of friction force microscopy (FFM). Experiments were performed with

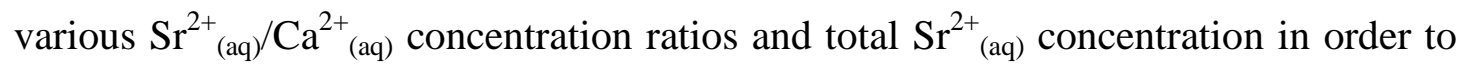
examine conditions under which Sr-calcite growth is self-limiting (e.g., the so-called "template effect") and also to investigate continuous Sr-calcite growth, where spiral growth predominates and $\mathrm{Sr}$ incorporation is sector-dependent. In these latter experiments, the goal was to evaluate the utility of friction force microscopy to discriminate sector zoning. Results from the experiments show that friction increases with the incorporation of $\mathrm{Sr}$ into the growing calcite layers. The maximum increase in friction was measured at high $\mathrm{Sr}^{2+}{ }_{(\mathrm{aq})} / \mathrm{Ca}^{2+}{ }_{(\mathrm{aq})}$, although a quantitative link between a specific amount of increase in friction to a specific amount of $\mathrm{Sr}$ incorporation was not possible to determine due to experimental uncertainties. Nevertheless it was possible to establish that no change in friction is detectable when $\mathrm{Sr}$ incorporation yields a solid composition of $\mathrm{Sr}_{0.05} \mathrm{Ca}_{0.95} \mathrm{CO}_{3}$. Friction was found to increase during growth of several layers in an incremental fashion. The increase can be linked either to an incremental increase in $\mathrm{Sr}$ content in the newly formed calcite, controlled by the thermodynamics of the strained layers necessitated by the substitution of larger $\mathrm{Sr}$ 
1 cations into the calcite, or to the incremental increase in layer thickness which in turn leads to increases in the probe-surface contact area. No difference in friction could be observed between acute and obtuse sectors under any of the experimental conditions, which was primarily due to the limits of the friction measurement sensitivity.

\section{INTRODUCTION} received considerable attention in the literature (Andersson et al., 2014; Bracco et al., 2012; Davis et al., 2004; Kohler et al., 2007; Lorens, 1981; Nielsen et al., 2013;

11 Paquette and Reeder, 1995; Reeder, 1996; Tesoriero and Pankow, 1996), due to the ubiquity of carbonates in the Earth's crust and their ability to interact with various divalent metals with significant environmental and geochemical implications. In particular, $\mathrm{Sr}^{2+}{ }_{(\mathrm{aq})}$ interactions with calcite have been studied due to calcite's potential use as a proxy for paleoenvironmental reconstructions (Carpenter and Lohmann, 1992; Stoll et al., 2002; Tang et al., 2008; Tang et al., 2012) and biocrystallisation (Lea et al., 1999), with studies spanning from bulk experiments (Mucci and Morse, 1983; Pingitore Jr et al., 1992; Tang et al., 2008; Tang et al., 2012), to microscale investigations using single crystals (Gabitov et al., 2014; Nehrke et al., 2007) to detailed nanoscale observations using atomic force microscopy (Astilleros et al., 2003a; Bracco et al., 2012; Wasylenki et al., 2005). Accordingly, the goals of these studies have been to study the Sr effect on crystal growth rates/mechanism, as well as its partitioning into the newly grown phase.

Atomic force microscopy observations by Astilleros et al. (2003a) showed a variety of phenomena on calcite surfaces exposed to $\mathrm{Sr}^{2+}$ (aq) solution, depending on the $\mathrm{Sr}^{2+}{ }_{(\mathrm{aq})}$ concentration. Among the observations was the so-called "template effect" at low $\mathrm{Sr}^{2+}$ (aq) concentrations $(\sim 0.2 \mathrm{mM})$, where monolayer growth is affected by the previously-grown underlayer and, at higher $\left.\mathrm{Sr}^{2+}{ }_{(\text {aq }}\right)$ concentrations $(\sim 2 \mathrm{mM})$, growth is followed by dissolution and precipitation of 3-D nuclei. Wasylenki et al. (2005) performed a detailed AFM study on the effect of Sr on spiral growth of calcite at low supersaturation. Their experiments were conducted with smaller $\mathrm{Sr}^{2+}$ (aq) concentrations and smaller $\mathrm{Sr}^{2+}{ }_{(\mathrm{aq})} / \mathrm{Ca}^{2+}{ }_{(\mathrm{aq})}$ ratio, as compared to those from Astilleros et al. (2003a). Wasylenki et al. (2005) found that calcite growth was brought to a complete halt once a certain value of $\mathrm{Sr}^{2+}$ (aq) concentration was achieved in the 
1 growing solution. This threshold concentration varied as a function of supersaturation.

2 Additionally, they performed segregation experiments on growth hillocks at low $3 \mathrm{Sr}^{2+}{ }_{(\mathrm{aq})}$ concentrations $(0.05 \mathrm{mM})$ and low $\mathrm{Sr}^{2+}{ }_{(\mathrm{aq})} / \mathrm{Ca}^{2+}{ }_{(\mathrm{aq})}$ ratios $(0.19)$ and found 4 preferential incorporation of $\mathrm{Sr}$ in the obtuse growth sector, verifying the observations made by Paquette and Reeder (1995). More recently, Bracco et al. (2012) found in their AFM investigations of Sr-calcite growth that the total inhibition of growth due to $\mathrm{Sr}^{2+}{ }_{\text {(aq) }}$ correlated with the $\mathrm{Ca}^{2+}{ }_{(\mathrm{aq})}$ concentration, but not the carbonate concentration, suggesting $\mathrm{Sr}$ inhibition occurred by blocking $\mathrm{Ca}$ attachment.

It has been shown in the past decade that friction force microscopy (FFM) can provide contrasting information on chemically-distinct surface overgrowths of nanometer thickness and at high lateral resolution (therefore, surpassing to some extent traditional surface analytical techniques such as X-ray Photoelectron Spectroscopy and Energy Dispersive X-ray analysis). With the ability to detect differences in composition at the nanometer scale, FFM may reveal new detail on the microstructure and chemistry of compositional boundaries in sedimentary minerals. For example, Hay et al. (2003) showed an increase in the lateral force signal for metal-bearing carbonates, including Sr, growing over a pure calcite substrate. Higgins and co-workers (Higgins and He, 2005; Higgins et al., 2007; Hu et al., 2010) reported friction differences, in aqueous solution, associated with non-stoichiometric dolomite overgrowths whereby Ca-rich films displayed increased friction over the native dolomite surface. Cubillas and Higgins (2009) performed a more detailed study on the friction change of cadmium-calcium carbonate overgrowths of different composition and demonstrated that FFM could detect very small compositional differences (5-10\% in $\mathrm{Cd}$ content) on calcite growth in the presence of $\mathrm{Cd}^{2+}{ }_{(\mathrm{aq})}$.

In this paper we present results from the study of $\mathrm{Sr}$ partitioning in calcite growth experiments by means of FFM. In an effort to assess the sensitivity of FFM to Sr levels in growing calcite, these experiments were designed to examine conditions under which Sr-calcite growth is self-limiting (e.g., the so-called "template effect") and also to investigate continuous Sr-calcite growth conditions, where spiral growth predominates. As shown in previous work by Paquette and Reeder (1995) and

31 Wasylenki et al. (2005), Sr is preferentially incorporated into obtuse steps on calcite 32 (104) surfaces. An additional objective of the current investigations is to evaluate the 33 utility of FFM for observing this specific type of sector zoning in calcite, where 34 differences in the overgrowths' chemical composition are expected to be very small. 


\section{MATERIALS AND METHODS}

\subsection{Experimental Set up}

Experiments were performed at room temperature $\left(25 \pm 2{ }^{\circ} \mathrm{C}\right)$ using a custombuilt AFM (Higgins et al., 1998) equipped with a closed flow cell and interfaced to an Agilent (Molecular Imaging) PicoScan 2500 SPM controller. The flow cell was designed to produce a vertically impinging solution jet onto the sample surface and laterally displaced by $2 \mathrm{~mm}$ from the tip/surface contact (Bose et al., 2008). All experiments were performed in contact mode using silicon cantilevers (Point Probe Plus-CONT). In some experiments, cantilever load was varied in order to observe its effect on the change of friction signal from the different overgrowths. Load was calculated using the deflection signal from the free position of the cantilever as the zero load point. Calibration of the load applied and friction force signal was carried out following the procedure described in detail in Cubillas and Higgins (2009).

Fresh calcite samples were prepared by cleaving optically clear Iceland Spar crystals (Ward's Natural Science Est. Inc.) along the (1014) plane using a razor blade. Minor and trace chemical analysis of crystals from the same batch are reported in $(\mathrm{Xu}$ et al., 2010). Typical sizes of the cleaved crystals were approximately $5 \mathrm{~mm}$ x $5 \mathrm{~mm}$ x $1 \mathrm{~mm}$. Samples were mounted into the fluid cell immediately after cleavage to prevent contamination. Prior to the start of the experiment, a calcite-undersaturated solution of $\mathrm{CaCl}_{2}(0.3 \mathrm{mM})$ and $\mathrm{NaHCO}_{3}(0.3 \mathrm{mM})(\mathrm{pH}=7.5$ - 8) was flushed through the cell to promote slow dissolution of the calcite sample and to generate etch pits. Afterwards, a solution containing the desired ion combinations was introduced. The total duration of the experiments varied between 2 and 20 hours. For experiments Sr-Calcite.1 to Sr-Calcite. 3 zoomed out scans were performed after the relevant scans were performed in order to evaluate possible tip-modified topography. These largerscale images (not shown) revealed that there was no tip scanning effect on the observed results. Fluid flow rate was maintained constant to $2.5 \pm 0.1 \mathrm{~g} / \mathrm{hr}$ using a Porter Instrument mass flow controller.

Solutions were prepared using de-ionized water (18 $\mathrm{M} \Omega$-cm resistivity), and high-purity $\mathrm{CaCl}_{2} \cdot 2 \mathrm{H}_{2} \mathrm{O}, \mathrm{NaHCO}_{3}, \mathrm{SrCl}_{2}$, and $\mathrm{NaOH}$. pH adjustment of the inlet 
1 the initial solution. Once the desired $\mathrm{pH}$ was achieved, the solution was injected into

2 the flow system by means of a $20 \mathrm{~mL}$ syringe. Re-equilibration kinetics of these

3 solutions with $\mathrm{CO}_{2}$ under the $\mathrm{pH}$ ranges used (8-9.5) were slow, so the $\mathrm{pH}$ measured

4 just before introducing the solution into the $\mathrm{CO}_{2}$-free flow system was considered to

5 be the $\mathrm{pH}$ of the solution in the flow cell where the calcite sample was located. $\mathrm{pH}$

6 measurements were carried out using an Accumet ${ }^{\circledR} \mathrm{pH} / \mathrm{ATC}$ Combination electrode

7 (Fisher Scientific 1961/Accumet) connected to a dual ion/pH meter from Fisher

8 Scientific. The $\mathrm{pH}$ electrode was calibrated using $\mathrm{pH} \mathrm{4,} \mathrm{7,} \mathrm{and} 10$ standard buffer

9 solutions from Fisher Scientific.

\subsection{Solid solution theory and saturation calculation}

It is well known that $\mathrm{SrCO}_{3}$ possesses an aragonite-type orthorhombic structure. Nevertheless, several authors have suggested that $\mathrm{Sr}$ can be incorporated into the structure of calcite (Astilleros et al., 2003a; Hay et al., 2003; Paquette and 14 Reeder, 1995; Pingitore and Eastman, 1986; Wasylenki et al., 2005). Astilleros et al. 15 (2003a) developed the thermodynamics of the Calcite- $\mathrm{SrCO}_{3 \text { (rhomb) }}$ solid solution (SS). Because a rhombohedral $\mathrm{SrCO}_{3}$ phase has never been observed nor experimentally precipitated, they calculated its solubility product using a theoretical approach, obtaining a value of $10^{-7.55}$. By taking into account the thermodynamics of the calcite-

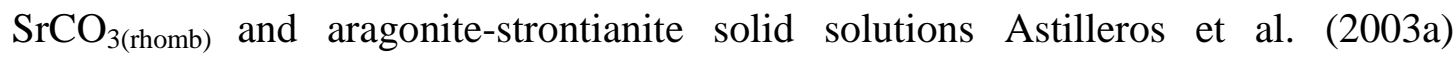
calculated a stability diagram for the whole $\mathrm{Sr}-\mathrm{Ca}$ compositional range, where it was found that for an aqueous mole fraction of $\mathrm{Sr}\left(\mathrm{X}_{\mathrm{Sr}}\right.$ aq $)$ of less than 0.125 the mineral with a calcite structure was the most stable, whereas for higher $\mathrm{Sr}^{2+}$ (aq) content the thermodynamically-favored phase had the aragonite type structure. They also predicted the existence of a miscibility gap between $0.15<\mathrm{X}_{\mathrm{Sr} \text {,aq }}<0.875$ for the aragonite-strontianite system.

Activities and saturation indices of the solutions were calculated using the program PHREEQC (Parkhurst and Appelo, 1999) and the PHREEQC database. Saturation index is defined as:

$$
\boldsymbol{S I}=\log \left(\frac{\boldsymbol{I A P}}{\boldsymbol{K}_{S P}}\right)
$$

where $\boldsymbol{I A P}$ is the ion activity product and $\boldsymbol{K}_{\boldsymbol{S P}}$ is the solubility product of the solid phase. The saturation state of a solid solution $(\mathrm{B}, \mathrm{C}) \mathrm{A}$ is not represented by a single value but is a function of both the solid and aqueous phase compositions. The general 


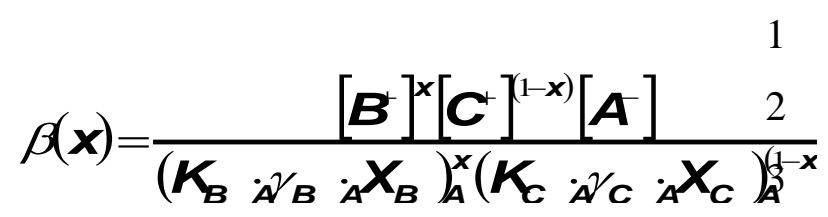

4 where $\left[\boldsymbol{A}^{-}\right]$refers to the activity of ion $\boldsymbol{A}$ in the aqueous solution, $\boldsymbol{K}_{\boldsymbol{B} \boldsymbol{A}}$ refers to the solubility product of the $\boldsymbol{B A}$ end-member, $\boldsymbol{X}_{\boldsymbol{B} \boldsymbol{A}}$ is the mole fraction, $\gamma_{B A}$ is its activity coefficient and $x=\boldsymbol{X}_{\boldsymbol{B} A}$. The maximum of the supersaturation function provides a good approximation of the precipitating solid-solution composition; nevertheless it does not take into account the kinetics of the nucleation process. More accurate predictions of the composition of the precipitating solid-solution requires this latter consideration (with the knowledge of a number of experimental parameters) as has been shown (Pina et al., 2000). The saturation states for the different solid solution compositions were calculated using the supersaturation function defined by Prieto et al. (1993). This function was added into PHREEQC as BASIC programming code.

Table 1 shows the chemical composition, the calculated saturation indices for

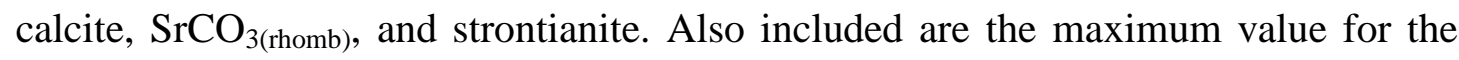
saturation index for the calcite- $\mathrm{SrCO}_{3 \text { (rhomb) }}$ solid solution $\left(\mathbf{S I}_{\max }\right)$ and its theoretical chemical composition $\left(\mathbf{X}_{\mathbf{S r}}\right)$ for all experiments performed. Experiments were divided into two groups. In the first group, compositions resemble those utilised by Astilleros et al. (2003a), which proved successful to drive monolayer and bi-layer growth and would, based on the SS model, achieve maximum Sr partitioning, among our experimental grid, in the overgrowth. The second group has a much smaller $\mathrm{Sr}^{2+}{ }_{(\mathrm{aq})}$ and $\mathrm{Ca}^{2+}{ }_{(\text {aq) }}$ content, and replicates the conditions used by Wasylenki et al. (2005) in their segregation experiments. These conditions produced continuous spiral growth and presumably lesser $\mathrm{Sr}$ incorporation into the growing crystal (as predicted by the SS model) than the first group of experiments.

\subsection{Data analysis}

A custom Matlab® code was written to batch process and analyze the lateral force data obtained from the AFM experiments. Friction values were computed by taking the difference in lateral deflection measured by a left-to-right scan and a rightto-left scan and dividing the difference by 2 . Usually, the scans do not overlap due to scanner hysteresis (i.e., features observed in forward and backward scans do not correspond to the same pixel positions along the fast-scan axis), so the code includes a 
1 "matching" subroutine, based on lateral deflection image cross-correlation, that 2 automatically overlaps both scans before calculating the friction. Several other 3 features were included in the code for "region of interest" (ROI) statistical analysis in 4 the images to obtain friction values and other statistical parameters over user-defined 5 areas, and for automated analysis of "friction loops" (Carpick and Salmeron, 1997; 6 Mate et al., 1987).

\section{RESULTS}

\subsection{Sr-rich carbonate layer growth}

Three experiments were carried out to determine if a composition contrast could be observed between layers of Sr-rich carbonate and the underlying calcium carbonate substrate. Solution composition was equal in all experiments except for a small variation in the $\mathrm{pH}$ (Table 1). Fig. 1 shows a series of AFM images (displaying both height and friction data) taken during experiment Sr-Calcite.2, which was performed at constant load $(6.8 \mathrm{nN})$ and constant scan rate $(6.1 \mathrm{~Hz})$. Fig. 1a shows an etch pit on the original calcite surface, just prior to the arrival of the Sr-bearing solution at the fluid cell's inlet orifice. The acute and obtuse steps are highlighted in the topography image. After the introduction of the $\mathrm{Sr}^{2+}{ }_{(\mathrm{aq})}$-rich solution, growth was observed as reflected by the step advancement in Fig. 1b, which was acquired 6 minutes after the first evidence of step advancement was observed. In Fig. 1b, the obtuse step position advanced by approximately $0.1 \mu \mathrm{m}$ whereas the acute step barely moved $(<70 \mathrm{~nm})$. The original positions of the steps are highlighted in the corresponding friction image demonstrating that there was a small increase in the friction on the newly grown monolayer. 10 min after the growth started, the etch pit was nearly filled due to the advancement of the obtuse step, which was irregular (Fig. 1c), whereas the acute step advanced with a speed nearly an order of magnitude lower. At the end of the image sequence, the etch pit was completely filled by the new layer and is only visible on the friction image due to its higher friction (Fig. 1d). No difference in friction is observed between the monolayer grown through advancement of the acute or obtuse steps, although the pit area that was filled by acute step advancement constitutes a very small region in the lower corner of the pit. 
Fig. 2 shows calibrated friction (in $\mathrm{nN}$ ) of the Sr-rich film and the calcite 2 substrate, as a function of time (after the data in Fig. 1b was collected) for experiment 3 Sr-Calcite.2. The Sr-rich monolayer displayed an average friction $15 \pm 3 \%$ higher 4 than that of the calcite substrate. This result corroborates the findings of Hay et al. 5 (2003) who also observed an increase in the measured lateral force when a Sr-rich 6 layer grew over a calcite substrate. Drift in the mean friction values probably resulted 7 from a poorly constrained experimental parameter, such as laser alignment 8 fluctuations which in turn affect load, as has been reported before (Cubillas and 9 Higgins, 2009)

10 Fig. 3 shows a series of AFM images from experiment Sr-calcite. 3 where two 11 layers of Sr-rich film were grown. Fig. 3a shows the initial etched calcite surface with 12 two steps highlighted. Fig. 3b, which was scanned 45 minutes after the new solution 13 was introduced, shows step advancement, signalling the start of growth. As was 14 observed before (Fig. 1) the new phase (labelled "Sr-1" in Fig. 3b) has a slightly 15 higher friction than the original calcite surface. The initial positions of steps 1 and 2 16 (labelled 1' and 2', respectively in Fig. 3b) are highlighted in the friction image. Once 17 the advancing steps reached the initial position of the underlying steps (1' and 2') the 18 subsequent growth rate decreased by almost an order of magnitude, in accordance 19 with what has been reported before (Astilleros et al., 2003a). Interestingly, the double 20 layer of $\mathrm{Sr}^{2+}{ }_{(\mathrm{aq})}$-rich solid solution (labelled "Sr-2" in Fig. 3c) has a higher friction 21 signal compared to the monolayer ( $\mathrm{Sr}-1)$. This fact is illustrated in Fig. 3c where step 222 has overrun the original position of step 1 (1') after 75 minutes of contact with the $23 \mathrm{Sr}^{2+}{ }_{(\mathrm{aq})}$-bearing solution. At the end of the experiment, water in equilibrium with $\mathrm{CO}_{2}$ $24(\mathrm{pH} \sim 6)$ was introduced into the AFM fluid cell promoting the dissolution of the 25 overgrowths. The dissolution process took place by step retreat as can be observed in 26 Fig. 3d by the position of steps 1 and 2. Evident in this figure is the friction difference 27 between calcite and the Sr-rich monolayer ( $\mathrm{Sr}-1)$, indicating that this difference is not 28 significantly influenced by the composition of the solution in contact with the scanned 29 surface (actual measured values are shown in Fig. 4). In this experiment no difference 30 in friction was found between the areas overgrown by obtuse and acute step 31 advancement.

32 Fig. 4 shows the measured friction as a function of time for calcite as well as 33 the Sr-bearing single and double layers for experiment Sr-Calcite.3. Differences in 34 friction between mono and double layer are smaller, c.a. $5 \pm 1 \%$, than those measured 
1 between calcite and a Sr-rich monolayer. In some cases, values on different surface regions are statistically similar, but clearly discernible on the images due to the spatial sorting of values between the two regions. A fluctuation in the computed friction values is also evident. As in Fig. 2, this variation could be due to laser signal fluctuations. The friction signal on calcite and the Sr-rich monolayer after the dissolution process started at the end of the experiment is also shown in Fig. 4 as the last 2 data points. The friction on the Sr-bearing layer was $15 \pm 3 \%$ larger than on the calcite surface. Experiment Sr-Calcite.1 yielded very similar results to those reported above, where the Sr-rich layer had a higher friction than the original calcite surface. In that experiment the friction increase on the Sr-bearing layer was also $15 \pm 3 \%$ relative to the native calcite surface.

\subsection{Spiral growth}

Because monolayer and double-layer growth experiments did not show any friction contrast between layers grown by the advancement of acute versus obtuse steps, it was hypothesized that the level of incorporation of $\mathrm{Sr}$ at the two different step edges may be a function of the growth conditions, namely the concentration of $\mathrm{Sr}^{2+}(\mathrm{aq})$ relative to $\mathrm{Ca}^{2+}(\mathrm{aq})$. With the goal of testing this hypothesis, a set of experiments (Sr-calcite.4 - Sr-calcite.5) were carried out on spiral growth hillocks where multiple layer growth was readily observed.

Pure calcite growth was promoted and then, once a spiral growth hillock was identified, a $\mathrm{Sr}^{2+}{ }_{\text {(aq) }}$-rich solution was introduced in the AFM fluid cell. Fig. 5 shows three AFM images of experiment Sr-calcite.4. Fig. 5a shows the growth spiral morphology under a Sr-free solution. Following this image, solution Sr-calcite.4.1 containing a Sr${ }^{2+}{ }_{(a q)} / \mathrm{Ca}^{2+}{ }_{(\mathrm{aq})}$ of 0.4 , was introduced. This Sr-bearing solution generated a progressive change in spiral morphology accompanied by a very small decrease (10$20 \%$ ) in the step advancement rate. The change of morphology after several Srbearing monolayers had been grown can be seen in Fig. 5b and 5c, in accordance with what has been published (Wasylenki et al., 2005). As was the case with previous experiments, no difference in the friction signal was observed between the acute and obtuse sectors.

Although sector zoning was not evident in friction measurements, an increase in the friction between the calcite substrate and the Sr-rich hillock was measured, in accordance with the observations reported in section 3.1. Fig. 6 shows this increase by 
1 displaying a plot of average friction (in volts) vs. time. The total number of layers 2 grown in the hillock is denoted by the numbers. For the first half of the experiment 3 (with solution $\mathrm{Sr}$-calcite.4.1), a total increase in the friction signal of c.a. $12 \pm 5 \%$ was 4 measured. The friction signal increased continuously with each new added layer until 5 it reached a roughly constant level after 4-5 new layers of Sr-rich solid solution had 6 been grown (shown with dotted horizontal line representing average friction from 7 layers 6-10),coinciding with the change of hillock morphology. After layer 10 was 8 grown, measurements were taken with a variable load. Results from these measurements at different loads are incompatible with the displayed values at constant load and are not shown, therefore leading to the break in the time axis. After

11 the variable load measurements, the load was returned to the same value as at the start 12 of the experiment, and solution $\mathrm{Sr}$-calcite.4.2, with a higher $\mathrm{Sr}^{2+}$ (aq) content $(0.07$ $13 \mathrm{mM})$ but the same $\mathrm{Ca}^{2+}{ }_{(\mathrm{aq})}$ content as Sr-calcite.4.1, was introduced $\left(\mathrm{Sr}^{2+}{ }_{(\mathrm{aq})} / \mathrm{Ca}^{2+}{ }_{(\mathrm{aq})}=\right.$ 14 1). This solution generated a further change in the hillock morphology, towards a 15 more elliptical shape (Fig. 5c), and a significant decrease in the step advancement speed (50\%). As in Fig. 5b, no difference in friction across growth sectors was observed with the higher concentration $\mathrm{Sr}^{2+}{ }_{(\mathrm{aq})}$. However, an additional increase in the overall hillock friction was observed, as can be seen in Fig. 6, which shows a corresponding increase of friction with additional layer growth. Horizontal lines show the average value of friction for each added monolayer. A total increase in friction of c.a. $40 \pm 7 \%$ was observed, which is a significantly larger change than those recorded in the first part of the experiment. Noticeable as well, is the fact that the measured friction just after the introduction of Sr-calcite.4.2 is very similar to the average value measured from layers 6-10 in the first half of the experiment, indicating that no significant change in friction occurred between the time the two measurements were taken (c.a. $35 \mathrm{~min})$

An additional experiment was carried out to further the previous observations (Sr-calcite.5). In this case, the $\mathrm{Sr}^{2+}{ }_{(\mathrm{aq})}$ content was increased to $0.21 \mathrm{mM}$ but $\mathrm{Ca}^{2+}{ }_{(\mathrm{aq})}$ was maintained at the same concentration as in experiment Sr-calcite.4, resulting in a $\mathrm{Sr}^{2+}{ }_{(\mathrm{aq})} / \mathrm{Ca}^{2+}{ }_{(\mathrm{aq})}$ ratio of 3. Fig. 7 shows three AFM images corresponding to the experiment. Fig. 7a was taken during the growth of calcite using a $\mathrm{Sr}^{2+}{ }_{(a q)}$-free solution. In this image it can be seen that a difference in friction already exists between the sectors, with the acute sector showing higher friction. Additionally, steps on the acute sector have a more roughened appearance than those on the obtuse 
1 sector. Also visible are a high number of surface voids, indicative of

2 defects/impurities in the surface, again with a higher density on the acute sector of the

3 hillock. In fact, the roughened appearance of the steps is visibly correlated to pinning

4 effects produced by these voids when the images are viewed in a time-lapse series.

5 Once the $\mathrm{Sr}^{2+}{ }_{(\mathrm{aq})}$-rich solution was introduced, the step speeds decreased by more than

$650 \%$ as the subsequent layer grew, and friction contrast was observed between the

7 pure calcite surface and the new Sr-rich layer ( $\mathrm{Sr}-1)$, as can be seen in the left (obtuse)

8 sector of the friction image in Fig. 7b. The measured friction difference between

9 calcite and the Sr-rich monolayer was $12 \pm 4 \%$. After the newly formed layer reached

10 the underlying step boundary (between pure calcite and Sr-rich calcite) growth of the

11 hillock nearly stopped (Fig. 7c), similar to that observed in the Sr-calcite.1 through

12 Sr-calcite. 3 experiments.

13

\section{DISCUSSION}

\subsection{Friction contrast due to Sr incorporation}

Sr incorporation into newly formed calcite was shown to produce an increase in the recorded friction with respect to that measured on pure calcite, in accordance with previous observations (Hay et al., 2003). Regardless of the $\mathrm{Sr}^{2+}{ }_{(\mathrm{aq})} / \mathrm{Ca}^{2+}{ }_{(\mathrm{aq})}$ utilized in these experiments, a significant increase in friction was observed (up to 40 $\%)$ with the growth of additional layers, up to about 5 layers. The increase was generally higher on a per layer basis for experiments where $\mathrm{Sr}^{2+}{ }_{(\mathrm{aq})} / \mathrm{Ca}^{2+}{ }_{(\mathrm{aq})}$ was the highest. In these high ratio experiments, a clear friction contrast between substrate and monolayer was observed, but in the low ratio experiments (Sr-calcite.4.1/4.2), the difference in friction increased continuously during growth (Fig. 6) and there was no evidence of friction contrast between adjacent layers.

Based on previous studies of the growth of Ca-rich films on dolomite ( $\mathrm{Hu}$ et al., 2010), the general observation of friction increase in the current study is related to the film strain that must accompany the incorporation of the larger $\mathrm{Sr}^{2+}$ into a lattice whose cell size is governed by the smaller $\mathrm{Ca}^{2+}$. In their study, $\mathrm{Hu}$ et al. (2010) observed that when a Ca-rich film grows conformally over dolomite, the larger size of the $\mathrm{Ca}^{2+}$ ions with respect to $\mathrm{Mg}^{2+}$ will increase the lateral strain in the film. This strain would be partially relieved by a vertical displacement of the ions over their preferred structural positions, as observed by X-ray reflectivity measurements (Fenter 
1 et al., 2007). This displacement in turn would lead to a lower stiffness of the film as

2 vertical displacement of the ions by the tip will require lower loads as compared with

3 a pure dolomite surface. In the present study we can envision that a similar situation

4 takes place as $\mathrm{Sr}^{2+}$ ions are significantly larger than $\mathrm{Ca}^{2+}$ (c.a. $18 \%$ ). In fact,

5 Astilleros et al. (2003a) reported an increase in the height of Sr-rich calcite films

6 relative to the pure calcite layer thickness. Even for the relatively small $\mathrm{Sr}^{2+}$ content

7 predicted to be incorporated in the films (Table 1), a sizeable vertical displacement

8 can be expected from those size differences, resulting in a more compliant film under 9 the AFM tip.

10 Although in the present study there were no observed height differences 11 between calcite step edges and step edges advancing in Sr-rich solution, the 12 mechanics of the probe-surface contact make height comparisons difficult. For 13 example, in the Johnson-Kendall-Roberts (JKR) (Johnson et al., 1971) model for 14 sphere-plane contacts, the area of contact is inversely related to the reduced elastic 15 modulus of the tip-surface contact, the latter of which will decrease if the Sr-rich film 16 has a lower Young's modulus than calcite. For a fixed tip radius, the increased 17 contact area on a more compliant film implies greater deformation of the film relative 18 to the calcite. Because height measurements between different materials in AFM are 19 only apparent determinations due to contact deformation, true film thickness data is 20 not readily available without fully accounting for probe-surface contact mechanics.

21 In contrast to the friction "mechanism" above, Murdaugh et al. (2007) noted 22 different friction behavior in heteroepitaxial films of $\mathrm{SrSO}_{4}$ and $\mathrm{PbSO}_{4}$ on barite and 23 suggested the adsorbed layer on top of the heteroepitaxial layer may influence 24 friction. The authors reported a decrease in friction relative to barite when self25 limiting (or autophobic) monolayer films of $\mathrm{PbSO}_{4}$ and $\mathrm{SrSO}_{4}$ were formed from 26 undersaturated solutions. The explanation for the decreased friction was based upon 27 the argument that solute ions (e.g., $\mathrm{Pb}^{2+}$ and $\mathrm{SO}_{4}{ }^{2-}$ ) had greater adsorption affinity to 28 the barite surface than to the film which is comprised of the same ions, thereby 29 leading to lower friction wherever the adsorbed ions were of lower concentration (i.e., 30 atop the film). This friction mechanism would, therefore, require a correlation 31 between the concentration of solute ions and the absolute friction observed on the 32 substrate. While plausible that the laterally sliding AFM probe must do additional 33 work on a surface that has adsorbates versus one that does not, Murdaugh et al. (2007) 34 do not report quantitative friction measurements before and after introduction of the 
1 solute, however, in Higgins et al. (2007), continuous friction measurements on a 2 dolomite (104) surface revealed no change in friction when the solute concentration 3 was increased, yet the autophobic film that subsequently developed did display an absolute friction increase. In the present study, we observed no change in friction on the calcite surface, or Sr-rich films, when the solute concentration was changed (see Fig. 4). Therefore, the increased friction observed on the Sr-rich layers in the current study is more consistently explained by the strained layer mechanism.

Through indirect evidence, the observation of rapid single layer growth followed by much slower subsequent growth (Fig. 3) implies a physical impediment to the growth of a second layer. This behaviour could be attributed to a progressive 11 change in the layer composition, as a higher concentration of $\mathrm{Sr}$ in the second layer will create a more strained layer, and therefore it will be more difficult to grow. Alternatively, second and subsequent layer growth, of layers of equal composition, may be inhibited by the presence of $\mathrm{Sr}^{2+}$ ions in the initial layer. That is, placement of the $\mathrm{Sr}^{2+}$ and $\mathrm{Ca}^{2+}$ ions into these subsequent layers may not be a random process, but instead may be dictated by the locations of $\mathrm{Sr}^{2+}$ and $\mathrm{Ca}^{2+}$ ions in the initial Sr-enriched film. In this scenario strain across subsequent layers would be reduced as the composition remains constant, but growth rates would be slowed by the kinetics of formation of this pseudo-ordered phase.

Friction contrast was not only observed between the first Sr-bearing layer and the pure calcite substrate, but also between the double and single Sr-rich layers, as shown by experiment Sr-calcite.3 (Figs. 3 and 4). This situation is similar to that observed for $\mathrm{Cd}^{2+}$ incorporation into calcite (Cubillas and Higgins, 2009) where the change in mechanical properties was purportedly driven by the increase in the thickness of the film (as the second layer grew), but more importantly, by a purported change in the composition of the layers as they grew. The arguments made in Cubillas and Higgins (2009) centered around the premise that higher Ca content in monolayer overgrowths would reduce strain on the film, and therefore rejection of the foreign ion was favoured, resulting in a single layer of intermediate composition followed by a second layer with a higher $\mathrm{Cd}^{2+}$ content (and presumably closer to the predicted composition from the SS thermodynamic model used in this study (section 2.2). Despite there being some undetermined relationship between film composition, strain and friction, it is possible to explain most of the friction trends using a single film 
1 thickness stems from likely changes in the mechanical properties of the tip-film-

2 calcite contact. That is, assuming all layers of the heteroepitaxial film to have the same composition, the underlying substrate's influence on the size of the tip-surface contact region will be a function of the film thickness alone because the stress field in the film/substrate will typically extend for several layers. For example, using the Hertz theory of a point load between materials, the compressive stress of the flat substrate under a load applied via a spherical object extends appreciably into the solid by a depth of more than 3 times the radius of the contact as derived in Johnson (Johnson, 1985):

$$
\sigma_{z}=-p_{o}\left(1+\frac{z^{2}}{r^{2}}\right)^{-1}
$$

Here, $z$ is the perpendicular distance into the solid substrate relative the surface $(z=$ $0), r$ is the contact radius, and $p_{o}$ is the maximum contact pressure. Furthermore Hertz theory predicts that the radius of contact will follow Equation (4):

$$
r=\left(\frac{3 P R}{4 E^{*}}\right)^{1 / 3}
$$

with $P$ representing the applied load, $R$ the radius of the spherical object and $E^{*}$ the reduced modulus comprised of the Young's moduli and Poisson ratios for the two materials. Assuming a tip radius of $20 \mathrm{~nm}$, a load of $10 \mathrm{nN}$, Young's moduli and Poisson ratios of $168 \mathrm{GPa}$ and 0.3 and $76 \mathrm{GPa}$ and 0.32 for silicon and calcite, respectively (Cubillas and Higgins, 2009) the contact radius would be about $1.4 \mathrm{~nm}$, suggesting that deformation of the calcite under ordinary contact AFM load conditions (few $\mathrm{nN}$ ) extends about 10 layers into the solid. The use of Hertz theory here is only meant for illustrative purposes and is not meant to imply that it is the best model to describe the contact mechanics in this system. Although it may be reasoned that the film composition could also change with additional layers, this scenario is not necessary to explain the observations, and because film composition is largely unknown, arguments based upon possible film compositional changes are exceedingly speculative. Therefore, even for an atomically sharp transition from calcite to Srcalcite, the transition in observed friction is expected to occur over several monolayers.

Despite the limitation in the surface selectivity of friction measurements, the

31 initial increase in the friction signal can be correlated to the amount of $\mathrm{Sr}^{2+}$ expected to be incorporated into the solid solution, as shown in Table 1. In the case of the first 
1 set of experiments (Sr-calcite.1 to Sr-calcite.3) a cation fraction composition of $\mathrm{X}_{\mathrm{Sr}}=$

20.125 was derived from the SS thermodynamic analysis. This composition

3 corresponds to the maximum theoretical amount of $\mathrm{Sr}^{2+}$ that can be incorporated into

4 the rhombohedral lattice, due to the existence of a miscibility gap in the phase

5 diagram for the solid solution (Astilleros et al., 2003a). In the present work, a friction

6 difference of c.a. $15 \pm 3 \%$ between monolayer and the calcite substrate was measured,

7 with an additional $5 \pm 1 \%$ increase relative to calcite determined on the double layer.

8 On the other hand, experiment Sr-calcite.4.1 showed a smaller friction difference

9 between the Sr-rich layers and the calcite substrate increasing incrementally with

10 every layer and reaching a total difference of $12 \pm 6 \%$ between the calcite substrate

11 and the 5-layers of Sr-rich overgrowth. For this experiment the calculated SS cation

12 fraction composition was $\mathrm{X}_{\mathrm{Sr}}=0.05$. In experiment Sr-calcite.5 the higher $\mathrm{Sr}^{2+}{ }_{(\mathrm{aq})}$

13 translated into a theoretical $\mathrm{Sr}^{2+}$ fraction of 0.12 . Accordingly, a higher increase in the

14 friction of a single monolayer was observed $(12 \pm 4 \%)$. Due to experimental 15 uncertainties and errors, it does not seem plausible that a percentage of $\mathrm{Sr}^{2+}$ 16 incorporation smaller than $5 \%$ would generate a statistically distinct friction signal. 17 Therefore, this would represent the "detection limit" of the technique to detect 18 chemical variation on the scanned surfaces.

\subsection{Lack of friction contrast between acute and obtuse sectors}

The absence of contrast in the measured friction between acute and obtuse sectors on the multilayer growth experiments can be explained in terms of the aforementioned "detection limit" for the technique, which will prevent observing compositional variations below a $\mathrm{X}_{\mathrm{Sr}}$ of 0.05 . In their segregation experiments, Wasylenki et al. (2005) observed a reduction of around $35 \%$ in the $\mathrm{Sr}^{2+}$ composition from obtuse to acute sectors. If we assume that the calculated $\mathrm{Sr}^{2+}$ fractions (Table 1) represent the incorporation in the obtuse steps (i.e. the maximum incorporation), then a $35 \%$ reduction in the acute sector will translate in an $\mathrm{X}_{\mathrm{Sr}}$ variation of around 0.04 . This value is below the "detection limit", and therefore explains why there is no

31 observable friction contrast between sectors. Regarding the friction contrast observation of the obtuse/acute boundary in experiment Sr-calcite.5 (Fig. 7), we can only hypothesize that it may be due to the greater presence of voids/impurities in the 
1 acute sector, as they will result in a greater surface roughness which in turn will translate to a larger recorded friction.

\section{CONCLUSIONS}

Friction force microscopy observations on the effect of $\mathrm{Sr}^{2+}$ incorporation during calcite growth at different $\mathrm{Sr}^{2+}{ }_{(\mathrm{aq})} / \mathrm{Ca}^{2+}{ }_{(\mathrm{aq})}$ ratios and various $\mathrm{Sr}^{2+}{ }_{(\mathrm{aq})}$ concentrations show an increase in the measured friction of up to $20 \%$ as the solid solution forms.

The total increase in friction can be qualitatively related to the theoretical amount of $\mathrm{Sr}^{2+}$ predicted to be incorporated in the newly formed solid solution, with solutions having higher $\mathrm{Sr}^{2+}{ }_{(\mathrm{aq})} / \mathrm{Ca}^{2+}{ }_{(\mathrm{aq})}$ ratio showing the largest increase in friction. Nevertheless, technique-related uncertainties made it impossible to correlate a given amount of $\mathrm{Sr}^{2+}$ incorporated with a given amount of friction increase. Still it was determined that a measurable change in friction could only be observed for a solid solution with an increase in $\mathrm{Sr}^{2+}$ content of at least $5 \%$, or $\mathrm{X}_{\mathrm{Sr}}=0.05$. The most likely explanation to account for the increase in the friction signal with $\mathrm{Sr}^{2+}$ incorporation is a decrease in the stiffness of the film due to vertical displacement of $\mathrm{Ca}^{2+}$ and $\mathrm{Sr}^{2+}$ positions derived from the need to accommodate the larger $\mathrm{Sr}^{2+}$ ions in the calcite structure.

Still, the increase in friction was observed to proceed across two or more layers. This can be explained, assuming a constant layer composition, by the changes in the mechanical properties of the tip-film-calcite contact, as the Sr-rich layers grow. For this system, the Hertz continuum mechanics model predicts that the stress field produced by the tip-film contact extends over 10 calcite monolayers. Therefore, as Srrich monolayers are added the mechanics of the contact will change, and thus the measured friction. In addition, the influence of the calcite substrate on the contact mechanics becomes more attenuated with time, resulting in the observed stabilisation of the measured friction with the number of layers grown.

No appreciable friction contrast was observed across obtuse and acute sectors for any experiment after introduction of a Sr-bearing solution. This does not rule out compositional contrast, but more likely, indicates that the fractional difference of $\mathrm{Sr}^{2+}$ incorporated at each sector was below 0.05 , considered to be the "detection limit" for the technique. 
2 Acknowledgments

3

4 The authors acknowledge the United States Department of Energy, Office of Science, 5 Basic Energy Sciences, Chemical Sciences, Geosciences and Biosciences Division

6 and the National Science Foundation Instrumentation and Facilities Program for

7 financial support of the research. Comments and suggestions from three anonymous

8 reviewers were highly beneficial in preparing revisions to the original manuscript. 
1 Table 1 Chemical composition, saturation indexes for pure phases and predicted 2 composition and supersaturation maximum for the newly formed solid solution for all 3 experiments performed.

\begin{tabular}{|c|c|c|c|c|c|c|c|c|c|c|}
\hline \multirow{2}{*}{ Experiment } & \multirow{2}{*}{$\begin{array}{l}\mathbf{S r}^{2+} \\
(\mathrm{mM})\end{array}$} & \multirow{2}{*}{$\begin{array}{l}\mathrm{Ca}^{2+} \\
(\mathrm{mM})\end{array}$} & \multirow{2}{*}{$\begin{array}{c}\mathrm{NaHCO}_{3} \\
(\mathrm{mM})\end{array}$} & \multirow{2}{*}{ pH } & \multirow{2}{*}{$\mathrm{Sr}^{2+} / \mathrm{Ca}^{2+}$} & \multirow{2}{*}{$\mathrm{SI}_{\text {cal }}$} & \multirow{2}{*}{$\mathrm{SI}_{\mathrm{Sr} \text { (romb) }}$} & \multirow{2}{*}{$\mathrm{SI}_{\mathrm{Sr}(\mathrm{orth})}$} & \multicolumn{2}{|c|}{ Calcite-SrCO ${ }_{3 \text { (romb) }} \mathrm{SS}$} \\
\hline & & & & & & & & & $\mathrm{SI}_{\max }^{\mathrm{a}}$ & $\mathbf{X}_{\mathrm{Sr}}^{\mathrm{b}}$ \\
\hline Sr-Calcite.1 & 10 & 3.2 & 0.8 & 8.0 & 3.13 & 0.04 & -0.37 & 1.36 & 0.16 & 0.125 \\
\hline Sr-Calcite.2 & 10 & 3.2 & 0.8 & 8.1 & 3.13 & 0.22 & -0.19 & 1.53 & 0.34 & 0.125 \\
\hline Sr-Calcite.3 & 10 & 3.2 & 0.8 & 8.12 & 3.13 & 0.27 & -0.16 & 1.56 & 0.38 & 0.125 \\
\hline Sr-Calcite.4.1 & 0.028 & 0.07 & 6 & 9 & 0.40 & 0.41 & -0.85 & 0.87 & 0.44 & 0.05 \\
\hline Sr-Calcite.4.2 & 0.07 & 0.07 & 6 & 9 & 1.00 & 0.41 & -0.46 & 1.26 & 0.47 & 0.11 \\
\hline Sr-Calcite.5 & 0.21 & 0.07 & 6 & 9 & 3.00 & 0.41 & 0.01 & 1.73 & 0.55 & 0.12 \\
\hline
\end{tabular}

4

5

6 a. Maximum reached by supersaturation function.

7 b. Solid solution composition corresponding to the maximum of the supersaturation 8 function.

9 


\section{$1 \quad$ Figure captions}

3 Figure 1. Height and friction AFM images for experiment Sr-Calcite.2 a) Calcite surface prior to the introduction of the Sr-rich solution. a) A dissolution etch pit can be clearly seen in the height image. Obtuse (1) and acute (2) steps are highlighted. b)

$615 \mathrm{~min}$. of growth the obtuse step position (1') has advanced $0.1 \mu \mathrm{m}$ approximately, whereas the acute step (2') has barely moved. c) 17 min after growth started the etch pit is nearly covered due to the irregular advancement of the obtuse step (1'). The acute step (2') has only advanced a fraction of the obtuse total displacement. d) After 19 min or growth the etch pit is completely covered by the overgrowth, and it shows a 11 constant friction.

13 Figure 2. Measured friction $(\mathrm{nN})$ as a function of time for calcite and the Sr-rich monolayer from experiment Sr-calcite. 2

Figure 3. Height and friction AFM images for experiment Sr-Calcite.3 a) Calcite surface prior to the introduction of the Sr-rich solution. Steps 1 and 2 are highlighted in the topography image. b) Image acquired $45 \mathrm{~min}$ after injecting the $\mathrm{Sr}$ rich solution. Steps 1 and 2 have advanced reflecting the growth of a new phase. The friction images reveal a difference in contrast between the new phase ( $\mathrm{Sr}-1)$ and calcite. The original positions of steps 1 and 2 are marked as 1' and 2'. c) Image scanned after 75 min of growth. Step 2 has advanced over the original position of step 1 (1') creating a double layer of $(\mathrm{Ca}, \mathrm{Sr}) \mathrm{CO}_{3}$. This double layer ( $\left.\mathrm{Sr}-2\right)$ shows higher friction than $\mathrm{Sr}-1$. d) Image acquired $95 \mathrm{~min}$. after the growth startedAt this point dissolution has taken over as can be seen from the retreated positions of steps 1 and 2 with respect to Fig. 3c. Friction contrast between Sr-1 layer and calcite is still evident.

Figure 4. Measured friction $(\mathrm{nN})$ as a function of time for calcite, $\operatorname{Sr}(1)$ and $\operatorname{Sr}(2)$ layers in experiment Sr-Calcite.3.

Figure 5. Height and Friction AFM images for experiment Sr-Calcite.4. a) Spiral on calcite growing in Sr-free solution. b) Same spiral as in (a) 90 minutes after the introduction of solutions Sr-Calcite4.1. A change in the spiral shape due to $\mathrm{Sr}$ 
1 incorporation is evident. c) Same spiral, 35 minutes after the introduction of solution

2 Sr-Calcite.4.2. A more striking change in shape is observed.

4 Figure 6. Average measured friction (V) as a function of time (min) for experiment 5 Sr-Calcite.4. Double arrows indicate the time when each solution was inside the fluid 6 cell. Numbers indicate the total number of layers formed on the hillock since the 7 introduction of the new solution composition.

8

9 Figure 7. Height and friction AFM images from experiment Sr-Calcite.5 a) Spiral 10 growing on Sr-free solution. Note the diference in friction between sectors and the 11 presence of small holes and ragged steps (height image), mainly on the acute sector.

12 b) Same spirals 8 minutes after the introduction of solution Sr-Calcite.5. A contrast in 13 friction is observed between the Sr-rich monolayer ( $\mathrm{Sr}-1)$ and the calcite substrate, 14 especially on the obtuse sector. c) Same spiral 28 minutes after introduction of the 15 growing solution. The Sr-1 monolayer has covered the substrate and growth rate has 16 decreased by at least an order of magnitude. Note that the friction contrast between 17 acute and obtuse sectors is maintained across the three sets of images. 


\section{References}

Andersson, M.P., Sakuma, H., Stipp, S.L.S., 2014. Strontium, Nickel, Cadmium, and Lead Substitution into Calcite, Studied by Density Functional Theory. Langmuir, 30(21): 6129-6133.

Astilleros, J.M., Pina, C.M., Fernandez-Diaz, L., Putnis, A., 2003a. Metastable phenomena on calcite $\{1014\}$ surfaces growing from $\mathrm{Sr}^{2+}-\mathrm{Ca}^{2+}-\mathrm{CO}_{3}{ }^{2-}$ aqueous solutions. Chemical Geology, 193(1-2): 93-107.

Bose, S., Hu, X., Higgins, S.R., 2008. Dissolution kinetics and topographic relaxation on celestite $\left(\begin{array}{lll}0 & 0 & 1\end{array}\right)$ surfaces: The effect of solution saturation state studied using Atomic Force Microscopy. Geochimica et Cosmochimica Acta, 72(3): 759-770.

Bracco, J.N., Grantham, M.C., Stack, A.G., 2012. Calcite Growth Rates As a Function of Aqueous Calcium-to-Carbonate Ratio, Saturation Index, and Inhibitor Concentration: Insight into the Mechanism of Reaction and Poisoning by Strontium. Crystal Growth \& Design, 12(7): 3540-3548.

Carpenter, S.J., Lohmann, K.C., 1992. ratios of modern marine calcite: Empirical indicators of ocean chemistry and precipitation rate. Geochimica et Cosmochimica Acta, 56(5): 1837-1849.

Carpick, R.W., Salmeron, M., 1997. Scratching the Surface: Fundamental Investigations of Tribology with Atomic Force Microscopy. Chemical Reviews, 97: 1163 - 1194.

Cubillas, P., Higgins, S.R., 2009. Friction characteristics of Cd-rich carbonate films on calcite surfaces: implications for compositional differentiation at the nanometer scale. Geochemical Transactions, 10.

Davis, K.J., Dove, P.M., Wasylenki, L.E., De Yoreo, J.J., 2004. Morphological consequences of differential $\mathrm{Mg} 2+$ incorporation at structurally distinct steps on calcite. American Mineralogist, 89(5-6): 714-720.

Fenter, P. et al., 2007. Structure and reactivity of the dolomite (104)-water interface: New insights into the dolomite problem. Geochimica et Cosmochimica Acta, 71(3): 566-579.

Gabitov, R.I., Sadekov, A., Leinweber, A., 2014. Crystal growth rate effect on $\mathrm{Mg} / \mathrm{Ca}$ and $\mathrm{Sr} / \mathrm{Ca}$ partitioning between calcite and fluid: $\mathrm{An}$ in situ approach. Chemical Geology, 367: 70-82.

Hay, M.B., Workman, R.K., Manne, S., 2003. Mechanisms of Metal Ion Sorption on Calcite: Composition Mapping by Lateral Force Microscopy. Langmuir, 19(9): 3727-3740.

Higgins, S.R., Eggleston, C.M., Knauss, K.G., Boro, C.O., 1998. A hydrothermal atomic force microscope for imaging in aqueous solution up to $150^{\circ} \mathrm{C}$. Review of Scientific Instruments, 69(8): 2994-2998.

Higgins, S.R., He, X.M., 2005. Self-limiting growth on dolomite: Experimental observations with in situ atomic force microscopy. Geochimica Et Cosmochimica Acta, 69(8): 2085-2094.

Higgins, S.R., Hu, X.M., Fenter, P., 2007. Quantitative lateral force Microscopy study of the dolomite (104)-water interface. Langmuir, 23(17): 8909-8915.

Hu, X., Cubillas, P., Higgins, S.R., 2010. Properties of Ca-Rich and Mg-Rich Carbonate Films on Dolomite: Implications for Compositional Surface Mapping with Scanning Force Microscopy. Langmuir, 26(7): 4769-4775.

Johnson, K.L., 1985. Contact Mechanics. Cambridge University Press.

Johnson, K.L., Kendall, K., Roberts, A.D., 1971. Surface energy and the contact of elastic solids. Proc R Soc London A, 324: 301 - 313. 
Kohler, S.J., Cubillas, P., Rodriguez-Blanco, J.D., Bauer, C., Prieto, M., 2007. Removal of cadmium from wastewaters by aragonite shells and the influence of other divalent cations. Environmental Science \& Technology, 41(1): 112118.

Lea, D.W., Mashiotta, T.A., Spero, H.J., 1999. Controls on magnesium and strontium uptake in planktonic foraminifera determined by live culturing. Geochimica et Cosmochimica Acta, 63(16): 2369-2379.

Lorens, R.B., 1981. Sr, Cd, Mn and Co distribution coefficients incalcite as a function of calcite precipitation rate. Geochimica et Cosmochimica Acta, 45: 553 - 561.

Mate, C.M., McClelland, G.M., Erlandsson, R., Chiang, S., 1987. Atomic-scale friction of a tungsten tip on a graphite surface. Physical Review Letters, 59: 1942-1945.

Mucci, A., Morse, J.W., 1983. The incorporation of magnesium(2+) ion and strontium(2+) ion into calcite overgrowths: influences of growth rate and solution composition. Geochimica et Cosmochimica Acta, 47(2): 217-33.

Nehrke, G., Reichart, G.J., Van Cappellen, P., Meile, C., Bijma, J., 2007. Dependence of calcite growth rate and $\mathrm{Sr}$ partitioning on solution stoichiometry: NonKossel crystal growth. Geochimica et Cosmochimica Acta, 71(9): 2240-2249.

Nielsen, L.C., De Yoreo, J.J., DePaolo, D.J., 2013. General model for calcite growth kinetics in the presence of impurity ions. Geochimica Et Cosmochimica Acta, 115: $100-114$.

Paquette, J., Reeder, R.J., 1995. Relationship between surface structure, growth mechanism, and trace element incorporation in calcite. Geochimica et Cosmochimica Acta, 59(4): 735-749.

Parkhurst, D.L., Appelo, C.A.J., 1999. User's guide to PHREEQC (Version 2) - A computer program for speciation, batch-reaction, one-dimensional transport and inverse geochemical calculations.

Pina, C.M., Enders, M., Putnis, A., 2000. The composition of solid solutions crystallizing from aqueous solutions: the influence of supersaturation and growth mechanisms. Chemical Geology, 168(3-4): 195-210.

Pingitore Jr, N.E. et al., 1992. Mode of incorporation of $\mathrm{Sr} 2+$ in calcite: Determination by X-ray absorption spectroscopy. Geochimica et Cosmochimica Acta, 56(4): 1531-1538.

Pingitore, N.E., Eastman, M.P., 1986. The coprecipitation of Sr2+ with calcite at 25 oC and $1 \mathrm{~atm}$. Geochimica et Cosmochimica Acta, 50: 2195-2203.

Prieto, M., Putnis, A., Fernandez-Diaz, L., 1993. Crystallization of solid solutions from aqueous solutions in a porous medium: zoning in ( $\mathrm{Ba}, \mathrm{Sr}) \mathrm{SO} 4$. Geological Magazine, 130(03): 289-299.

Reeder, R.J., 1996. Interaction of divalent cobalt, zinc, cadmium and barium with the calcite surface during layer growth. Geochimica et Cosmochimica Acta, 60: $1543-1552$.

Stoll, H.M., Rosenthal, Y., Falkowski, P., 2002. Climate proxies from Sr/Ca of coccolith calcite: calibrations from continuous culture of Emiliania huxleyi. Geochimica et Cosmochimica Acta, 66(6): 927-936.

Tang, J., Köhler, S.J., Dietzel, M., 2008. Sr2+/Ca2+ and 44Ca/40Ca fractionation during inorganic calcite formation: $\mathrm{I}$. $\mathrm{Sr}$ incorporation. Geochimica et Cosmochimica Acta, 72(15): 3718-3732.

Tang, J. et al., 2012. Sr2+/Ca2+ and 44Ca/40Ca fractionation during inorganic calcite formation: III. Impact of salinity/ionic strength. Geochimica et Cosmochimica Acta, 77(0): 432-443. 
1 Tesoriero, A.J., Pankow, J.F., 1996. Solid solution partitioning of Sr2+, Ba2+, and 2 Cd2 + to calcite. Geochimica et Cosmochimica Acta, 60(6): 1053-1063.

3 Wasylenki, L.E., Dove, P.M., Wilson, D.S., DeYoreo, J.J., 2005. Nanoscale effects of 4 strontium on calcite growth: An in situ AFM study in the absence of vital 5 effects. Geochimica et Cosmochimica Acta, 69: 3017-3027.

6 Xu, M., Hu, X.M., Knauss, K.G., Higgins, S.R., 2010. Dissolution kinetics of calcite 7 at 50-70 degrees $\mathrm{C}$ : An atomic force microscopic study under near-equilibrium conditions. Geochimica Et Cosmochimica Acta, 74(15): 4285-4297. 
1
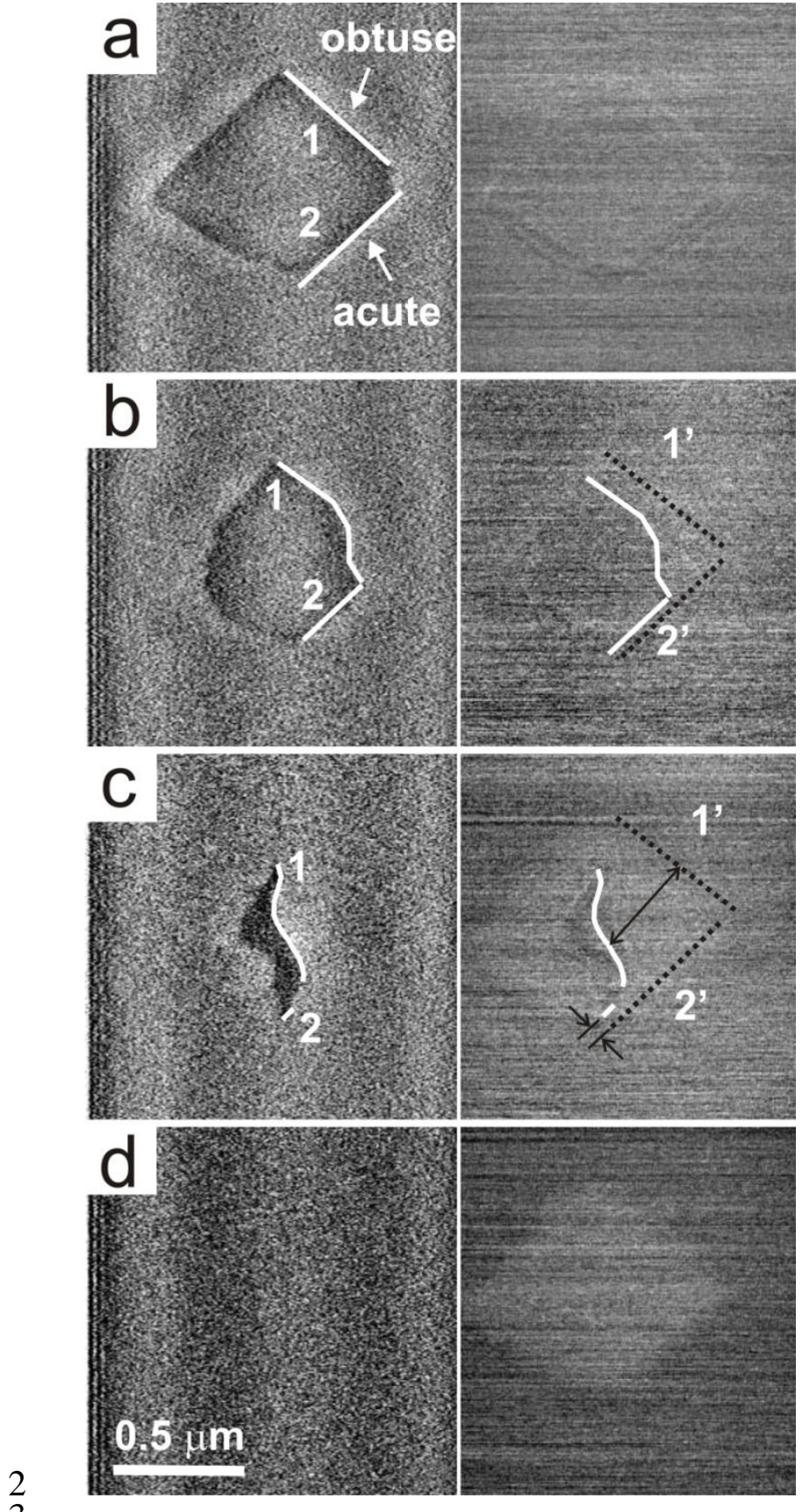

Figure 1

5 


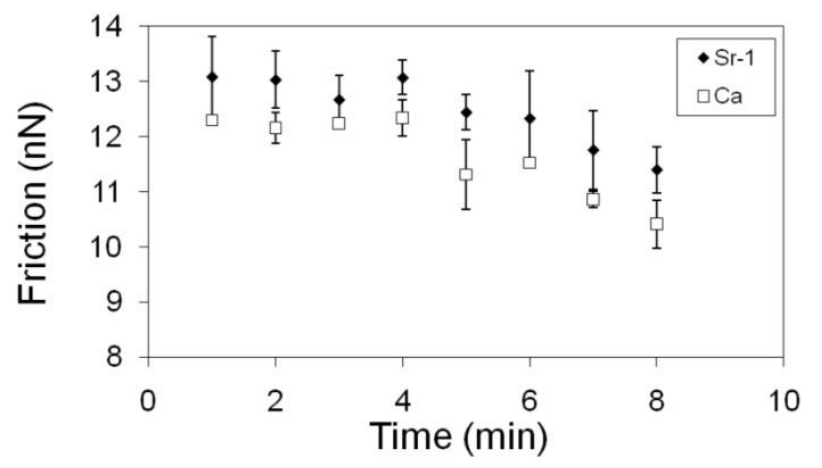

Figure 2

4 

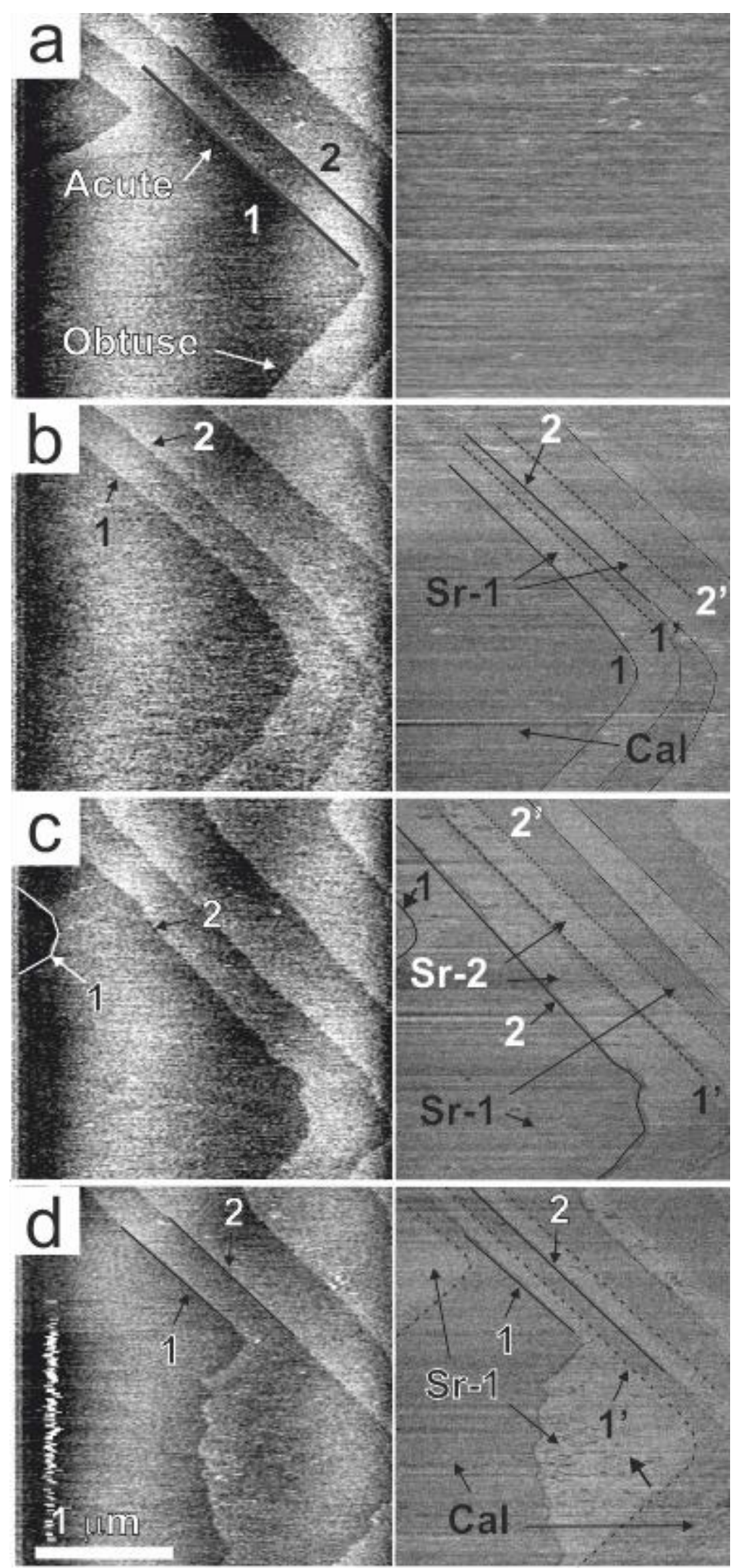

Figure 3 


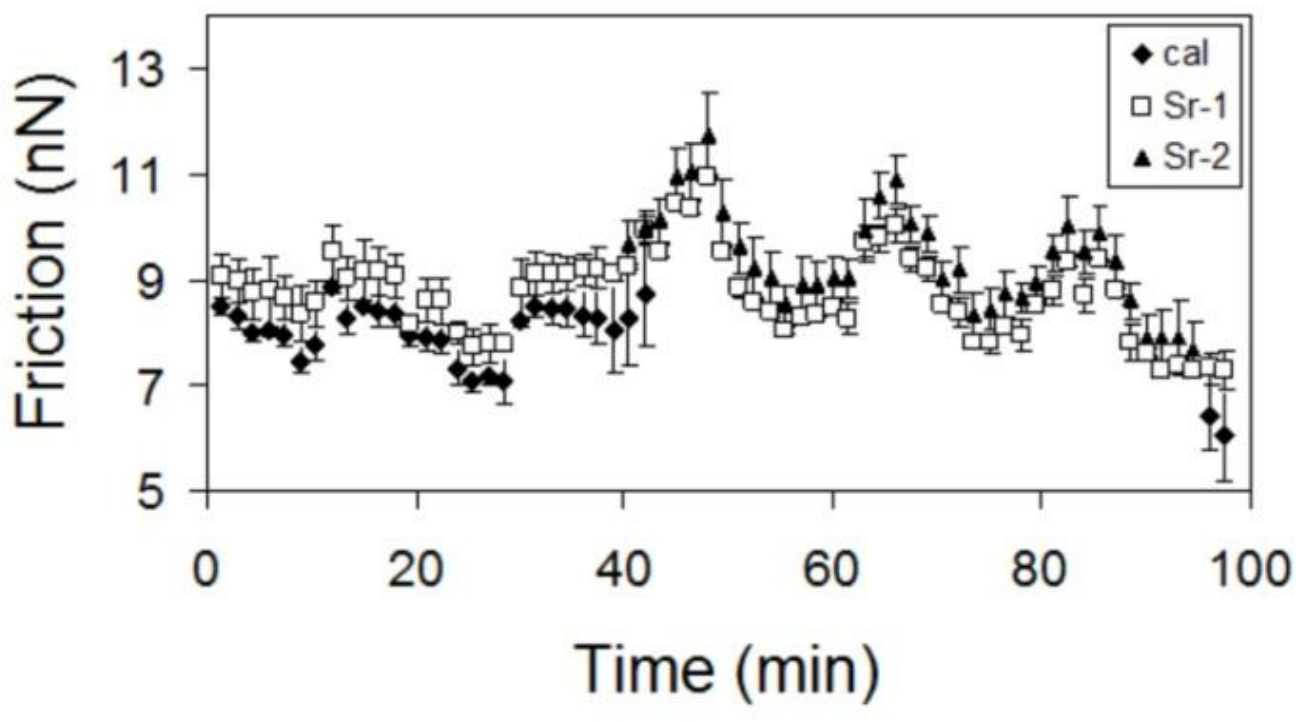

Figure 4 

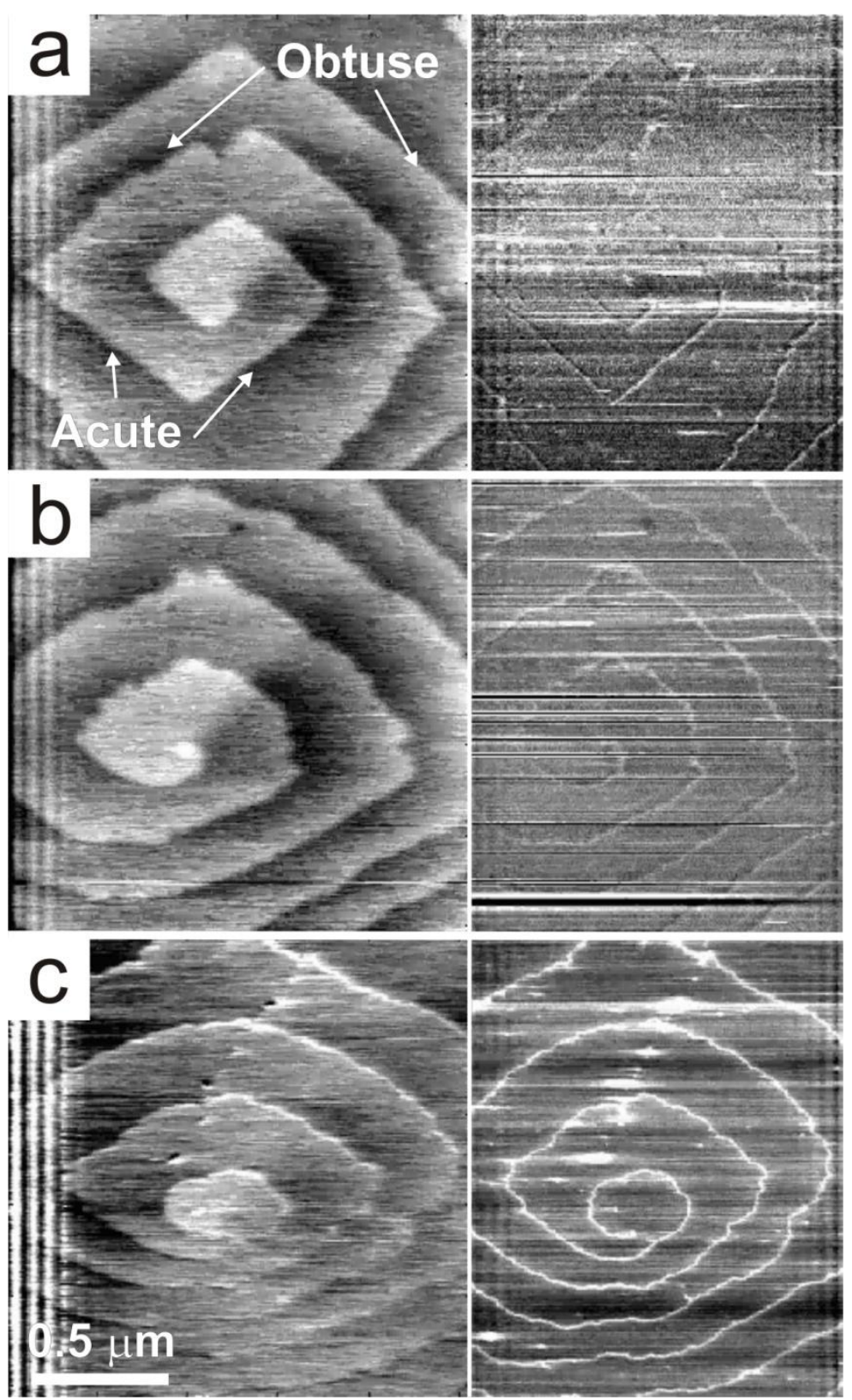

Figure 5 


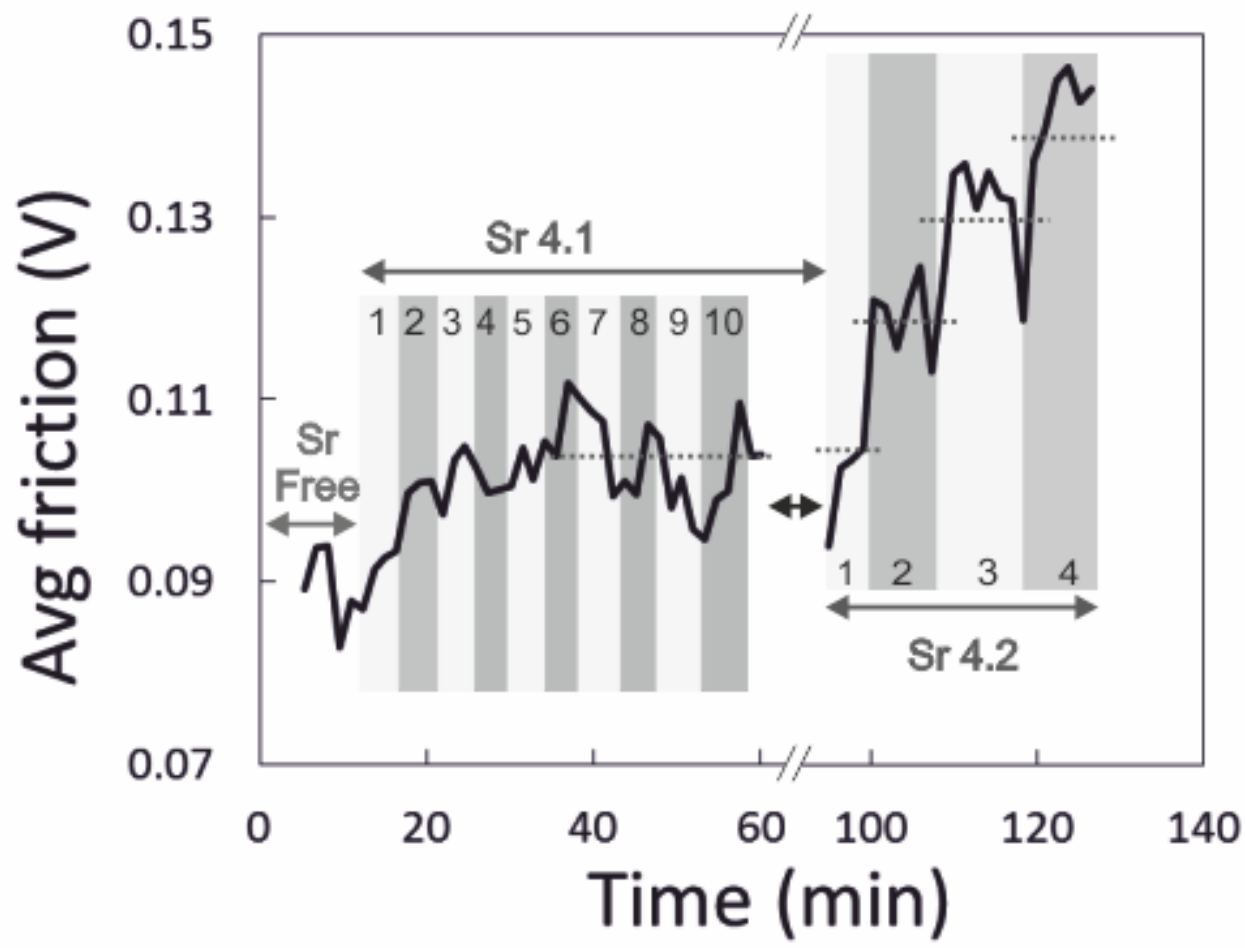

Figure 6 

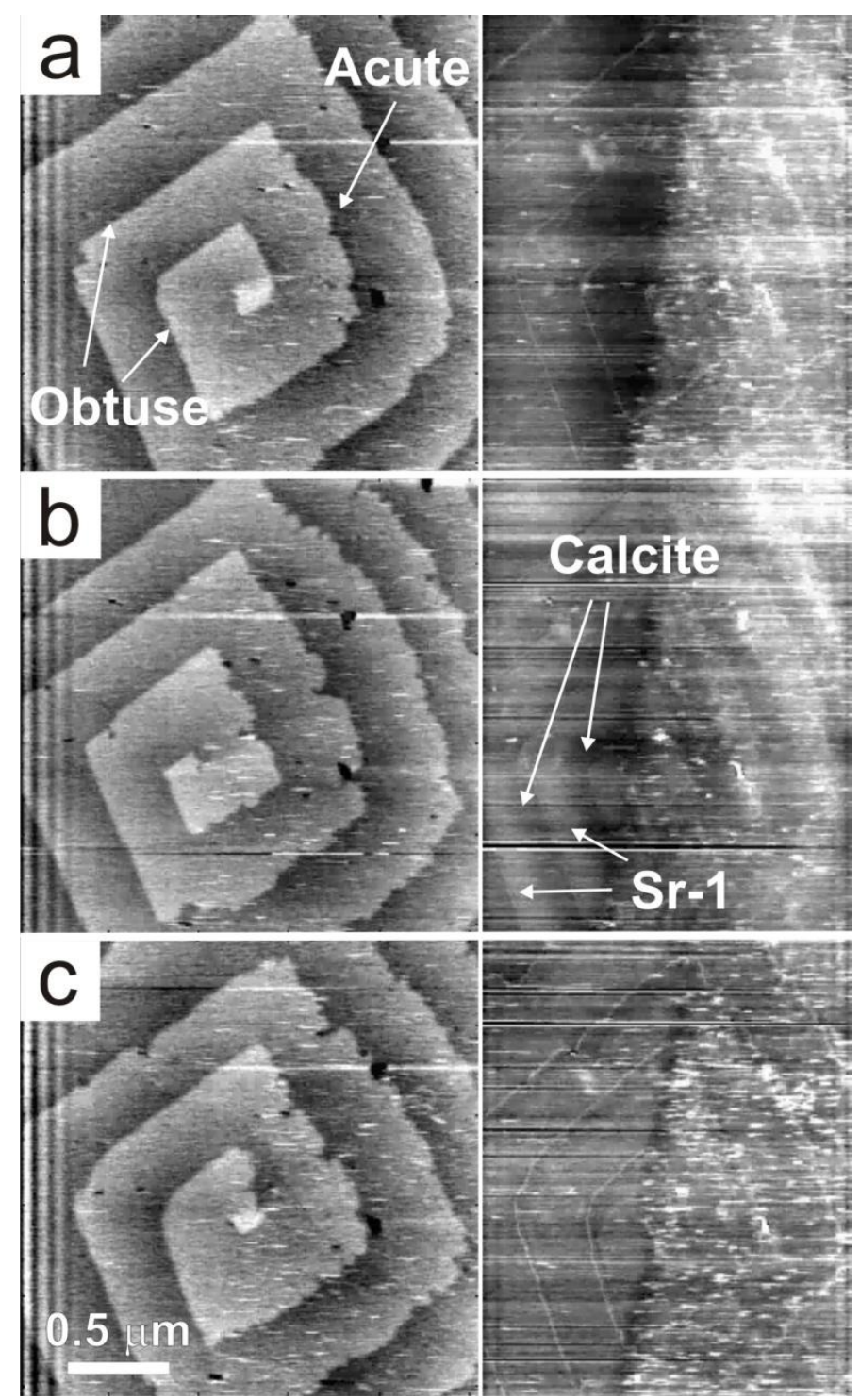

\section{Figure 7}


Click here to download high resolution image
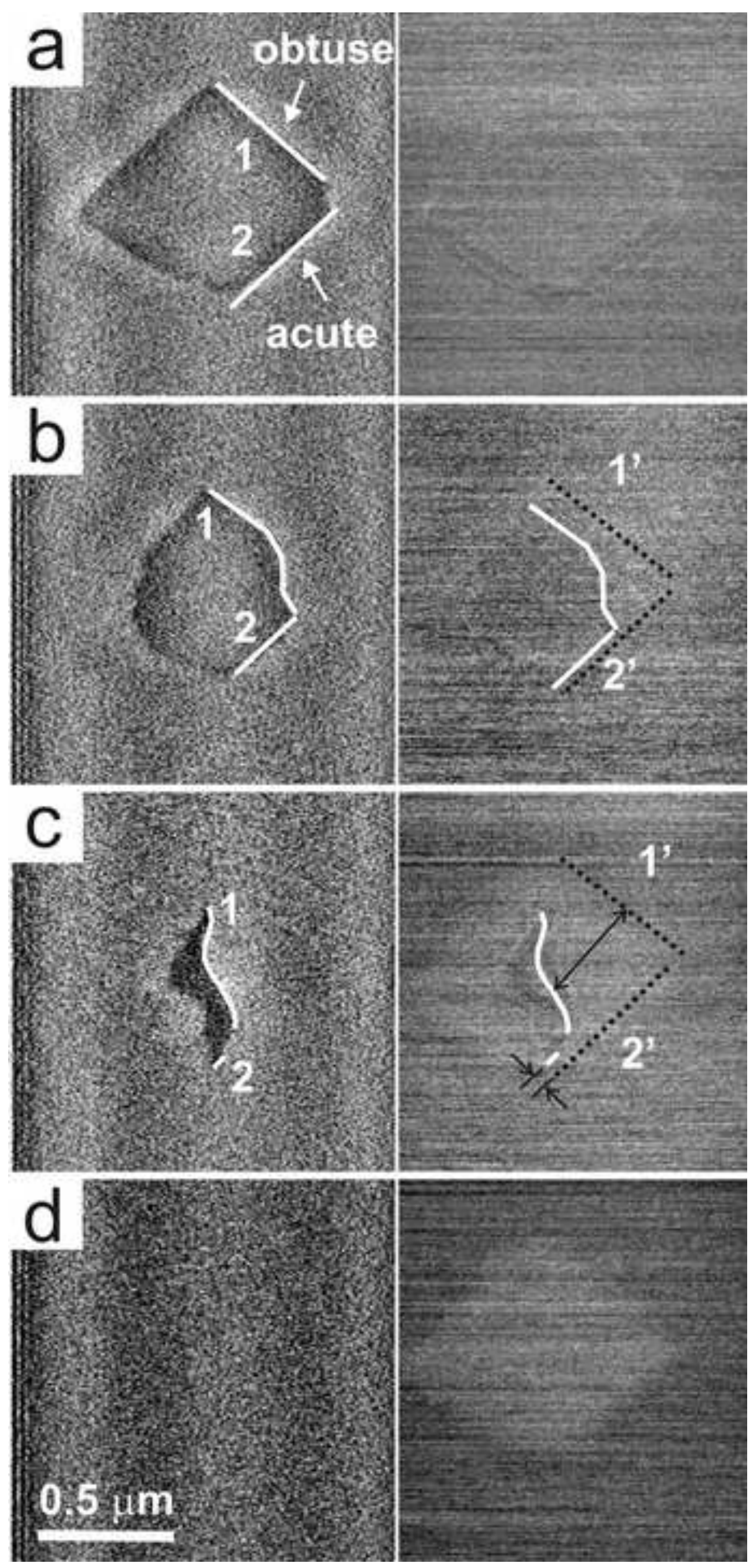


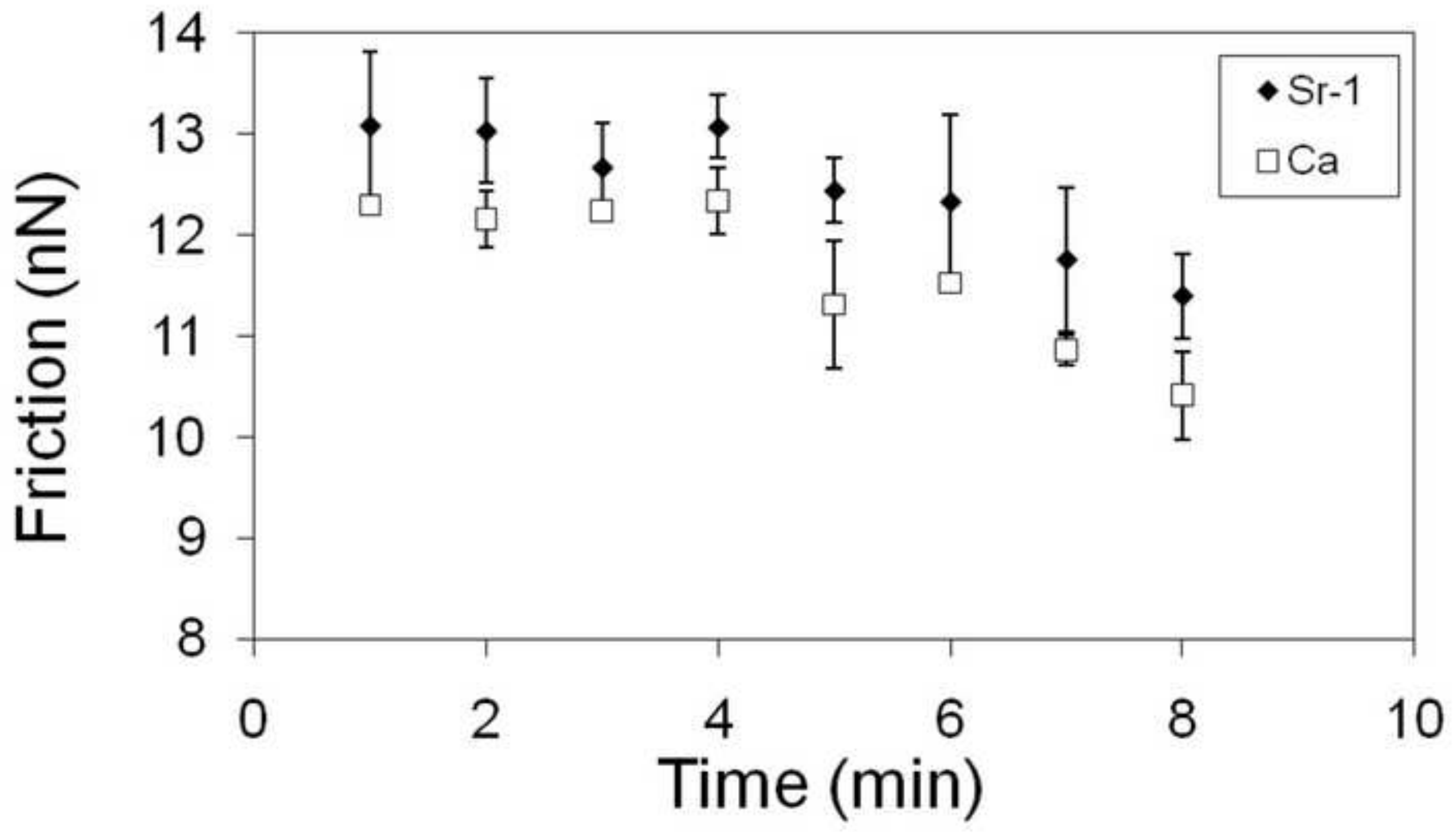


Click here to download high resolution image
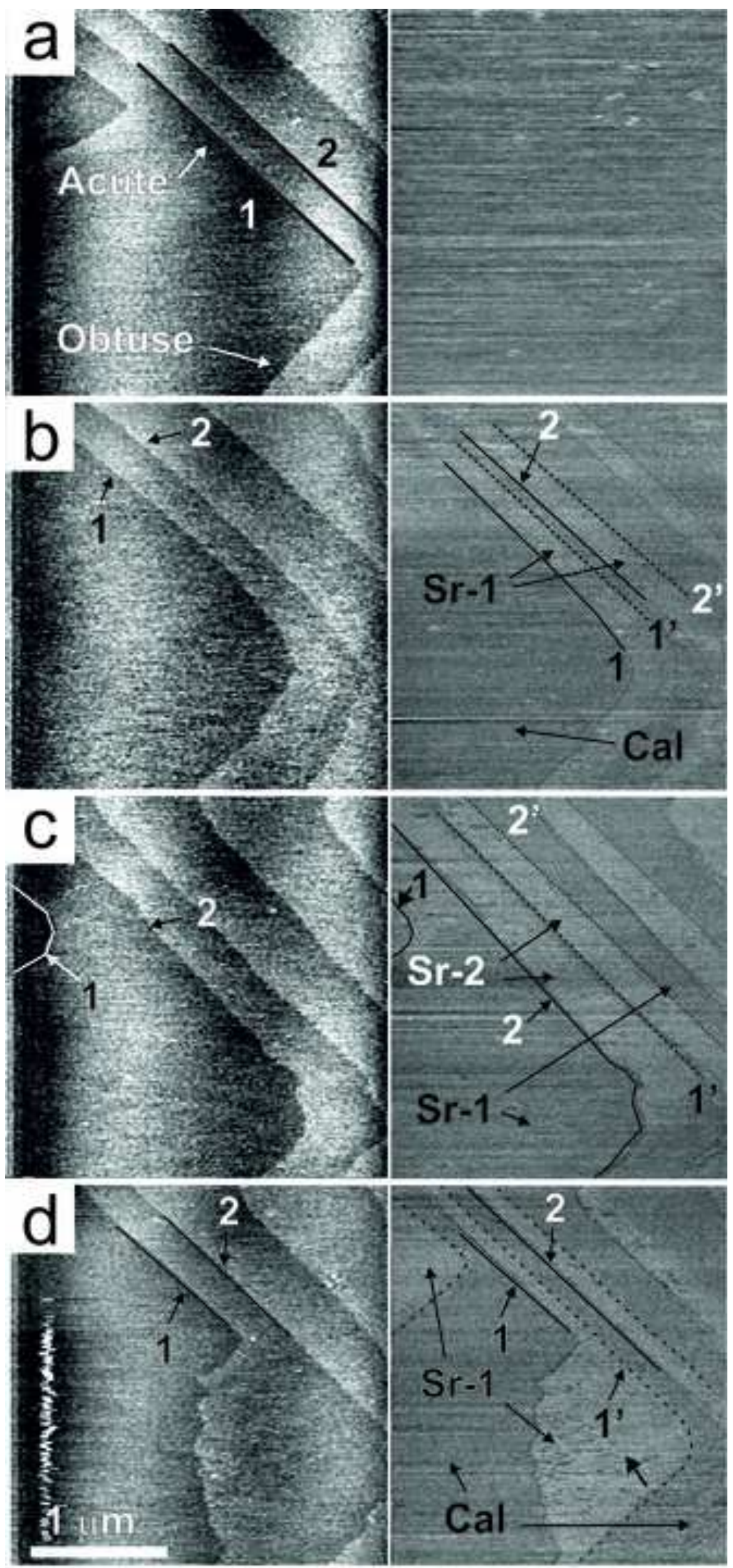


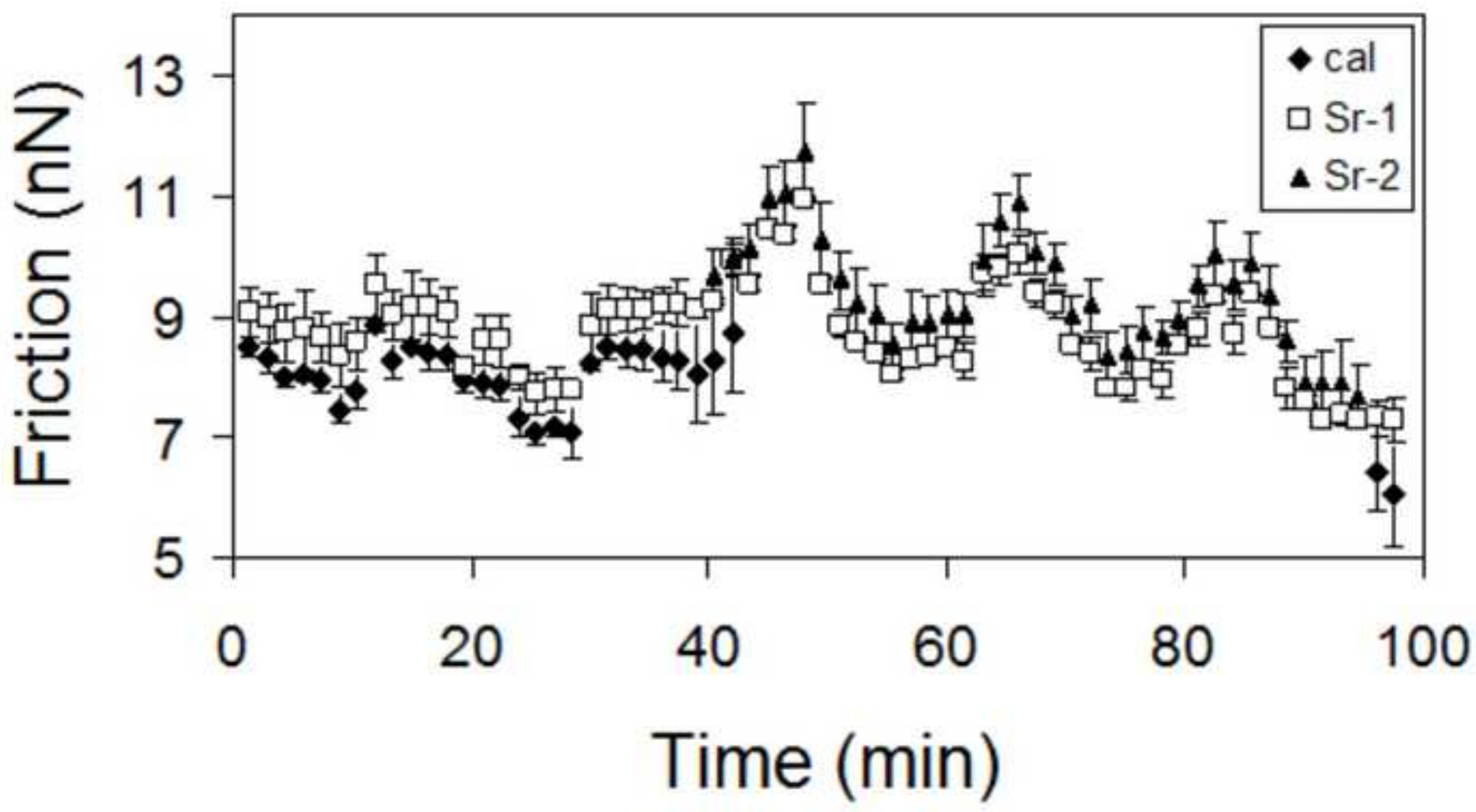


Figure 5

Click here to download high resolution image
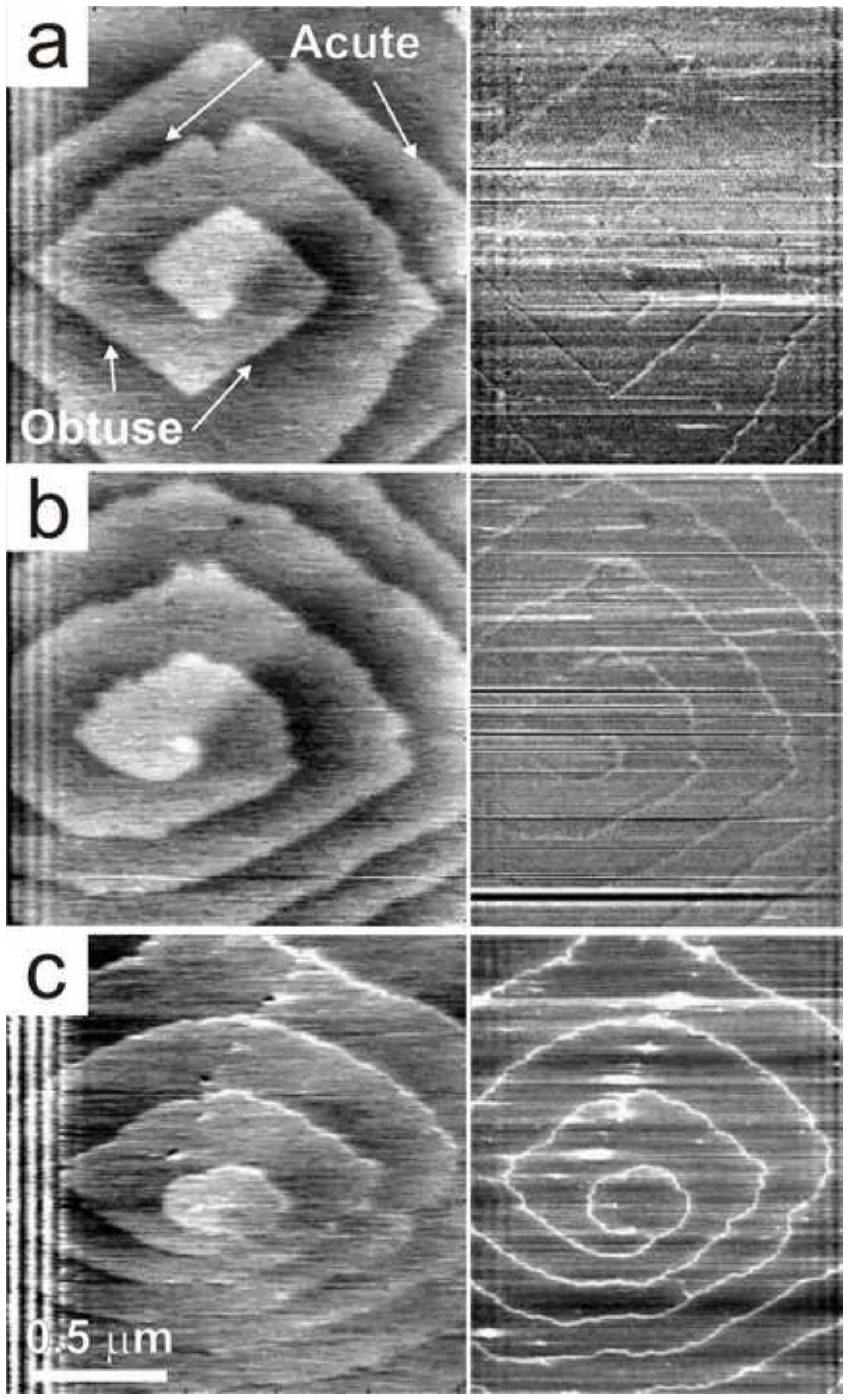


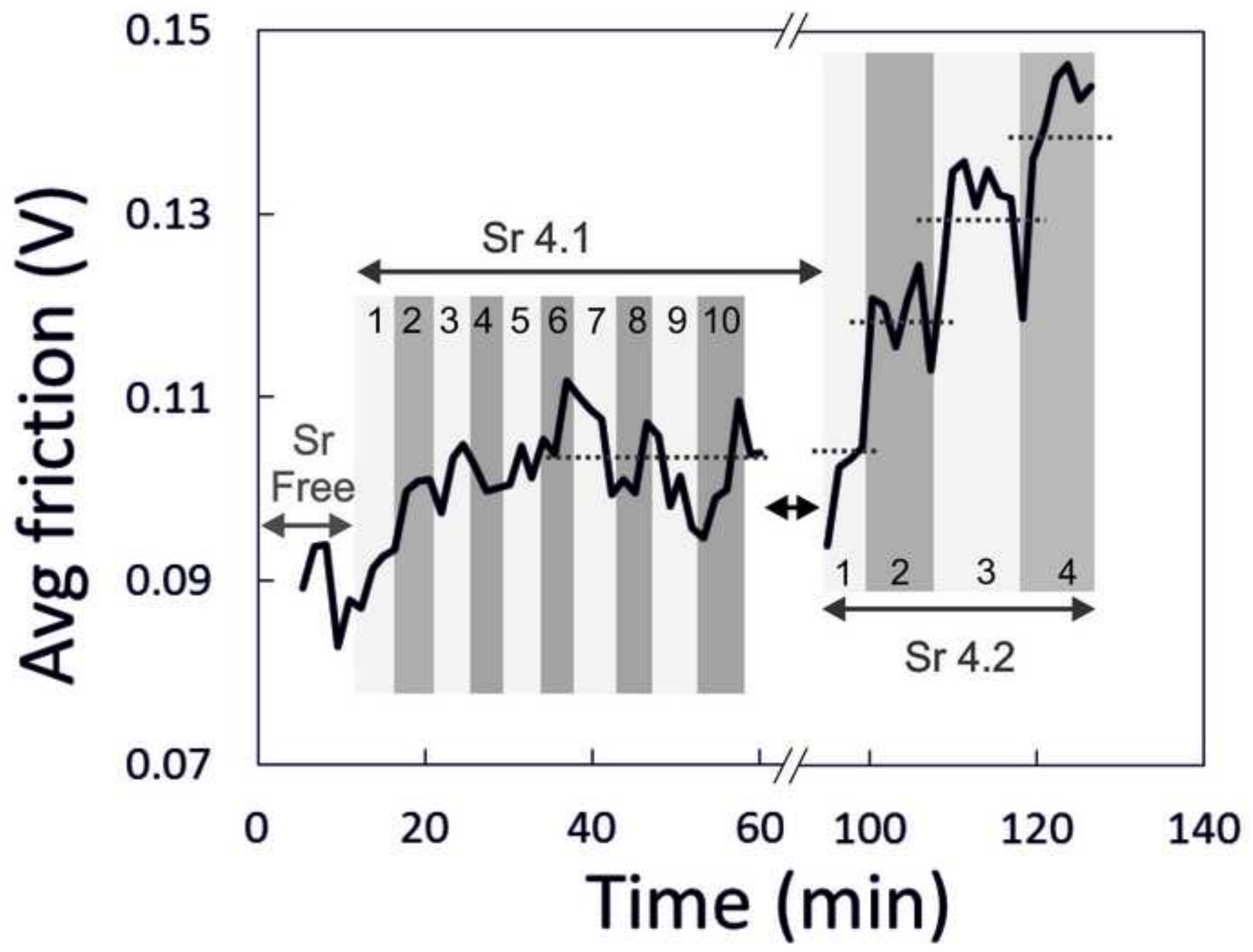




\section{Figure 7}

Click here to download high resolution image
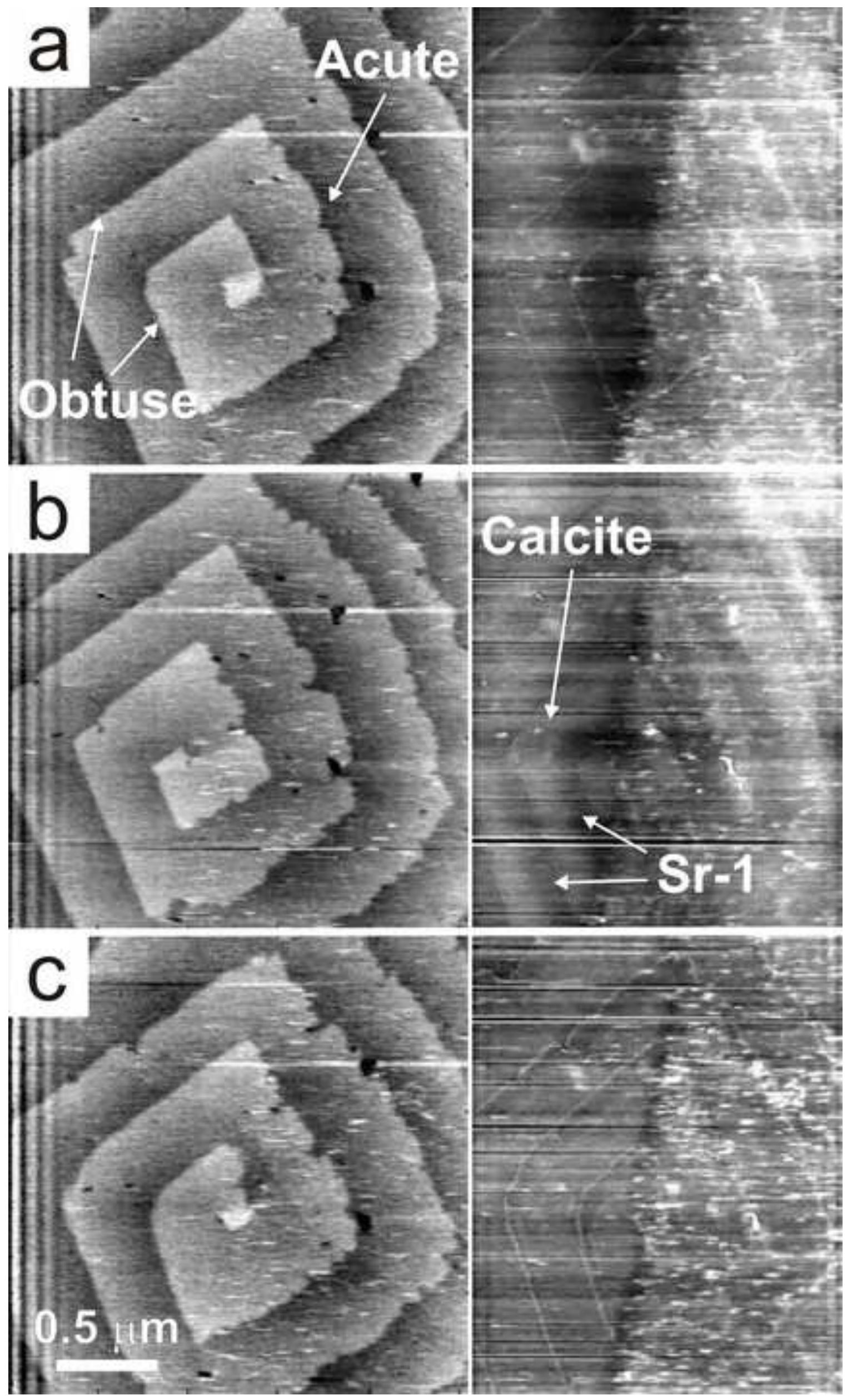